\title{
Retinoic acid prevents mesenteric lymph node dendritic cells from inducing IL-13-producing inflammatory Th2 cells
}

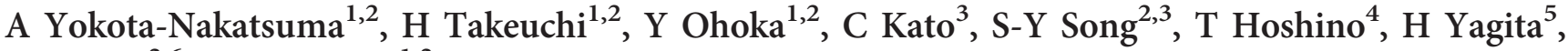 \\ $\mathrm{T}$ Ohteki ${ }^{2,6}$ and $\mathrm{M}$ Iwata $^{1,2}$
}

The vitamin A (VA) metabolite retinoic acid (RA) affects the properties of Tcells and dendritic cells (DCs). In VA-deficient mice, we observed that mesenteric lymph node (MLN)-DCs induce a distinct inflammatory T helper type 2 (Th2)-cell subset that particularly produces high levels of interleukin (IL)-13 and tumor necrosis factor- $\alpha$ (TNF- $\alpha$ ). This subset

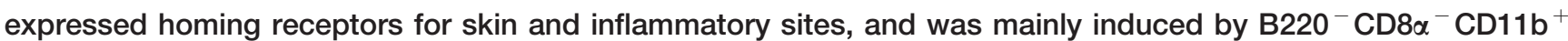
CD103- MLN-DCs in an IL-6- and OX40 ligand-dependent manner, whereas RA inhibited this induction. The corresponding MLN-DC subset of VA-sufficient mice induced a similar T-cell subset in the presence of RA receptor antagonists. IL- 6 induced this subset differentiation from naive CD4 ${ }^{+}$T cells upon activation with antibodies against CD3 and CD28. Transforming growth factor- $\beta$ inhibited this induction, and reciprocally enhanced Th17 induction. Treatment with an agonistic anti-OX40 antibody and normal MLN-DCs enhanced the induction of general inflammatory Th2 cells. In VA-deficient mice, proximal colon epithelial cells produced TNF- $\alpha$ that may have enhanced OX40 ligand expression in MLN-DCs. The repeated oral administrations of a T cell-dependent antigen primed VA-deficient mice for IL-13-dependent strong immunoglobulin G1 (IgG1) responses and IgE responses that caused skin allergy. These results suggest that RA inhibits allergic responses to oral antigens by preventing MLN-DCs from inducing IL-13-producing inflammatory Th2 cells.

\section{INTRODUCTION}

Vitamin A (VA) and its metabolite retinoic acid (RA) play critical roles in gut immunity. VA supplementation significantly reduces the mortality of undernourished infants, largely by reducing the severity of infectious diarrhea. ${ }^{1}$ VA or RA deficiency is also induced by fat malabsorption resulting from disorders, such as pancreatic insufficiency, cholestatic liver diseases, cystic fibrosis, sprue, or inflammatory bowel diseases, or from defective VA metabolism as observed in alcoholism. ${ }^{2-4}$ Dendritic cells (DCs) in gut-related lymphoid organs express the key RA-generating enzyme retinal dehydrogenase 2 (RALDH2; aldehyde dehydrogenase 1A2, ALDH1A2) and thus can produce RA from retinol, the basic form of VA. ${ }^{5,6}$ $\mathrm{RALDH}_{2}{ }^{+}$DCs express CD103, and these cells also exist in the lamina propria of the small intestine. ${ }^{7-9} \mathrm{RA}$ imprints guthoming specificity on naive $\mathrm{T}$ and $\mathrm{B}$ cells upon activation. ${ }^{5,10}$ Thus, VA deficiency causes the depletion or reduction of $\mathrm{T}$ cells and immunoglobulin A (IgA)-producing B cells from the small intestinal lamina propria. RA also regulates the functional differentiation of $\mathrm{T}$ cells. It suppresses $\mathrm{T}$ helper type 1 (Th1) differentiation both directly and indirectly, and reciprocally enhances Th2 differentiation under certain conditions. ${ }^{11}$ Accordingly, VA deficiency reduces antibody responses to $\mathrm{T}$ cell-dependent antigens and $\mathrm{T}$ cell-independent type 2 antigens but not $\mathrm{T}$ cell-independent type 1 antigens such as lipopolysaccharide. ${ }^{12,13} \mathrm{RA}$ also enhances the transforming growth factor- $\beta$ (TGF- $\beta$ )-dependent generation of forkhead box P3 (Foxp3) ${ }^{+}$inducible regulatory $\mathrm{T}$ cells, but suppresses

\footnotetext{
${ }^{1}$ Laboratory of Immunology, Kagawa School of Pharmaceutical Sciences, Tokushima Bunri University, Kagawa, Japan. ${ }^{2}$ JST, CREST, Tokyo, Japan. ${ }^{3}$ Institute of Neuroscience, Tokushima Bunri University, Kagawa, Japan. ${ }^{4}$ Department of Medicine, Kurume University School of Medicine, Fukuoka, Japan. ${ }^{5}$ Department of Immunology, Juntendo University School of Medicine, Tokyo, Japan and ${ }^{6}$ Department of Biodefense Research, Medical Research Institute, Tokyo Medical and Dental University, Tokyo, Japan. Correspondence: M Iwata (iwatam@kph.bunri-u.ac.jp)
}

Received 14 March 2013; accepted 12 October 2013; published online 13 November 2013. doi:10.1038/mi.2013.96 
Th17 generation. ${ }^{7,8,14}$ The RA-dependent generation of guttropic Foxp $3^{+}$inducible regulatory $\mathrm{T}$ cells appears to be important for oral tolerance. ${ }^{15-17}$ However, the generation of Th1 and Th17 cells also appears to require RA. ${ }^{18,19}$ Furthermore, in conjunction with IL-15, RA acts as an adjuvant to promote Th1-dependent inflammation. ${ }^{20} \mathrm{VA}$ or RA deficiency also affects the nature of DCs, especially mesenteric lymph node (MLN)-DCs. RALDH2 expression is nearly absent in MLN-DCs of $\mathrm{VA}(-)$ mice. ${ }^{6,9,21}$ The langerin ${ }^{+} \mathrm{CD} 8 \alpha^{-}$ $\mathrm{CD}_{11 \mathrm{~b}} \mathrm{~b}^{\text {low } /+} \mathrm{CD}_{103}{ }^{+}$DC population increases in MLNs. ${ }^{22}$

Here we unexpectedly found that MLN-DCs of unprimed $\mathrm{VA}(-)$ mice induced the differentiation of naive $\mathrm{CD} 4{ }^{+} \mathrm{T}$ cells to a distinct subset of inflammatory Th2 cells that particularly produced high levels of interleukin-13 (IL-13) and tumor necrosis factor- $\alpha$ (TNF- $\alpha$ ) as well as Th17 cells. IL-6- and OX40 ligand (OX40L)-mediated signals appeared to be required for the optimal induction of these IL-13-producing inflammatory Th2 cells, whereas TGF- $\beta$ suppressed the induction. Th17 cytokines contribute to inflammatory and autoimmune diseases, ${ }^{23}$ whereas IL-13 plays critical roles in inflammatory and allergic diseases including asthma, ${ }^{24-27}$ ulcerative colitis, ${ }^{28,29}$ and atopic dermatitis. ${ }^{30}$ IL-13 is also a major stimulator of tissue remodeling and fibrosis in various tissues, including the liver, lungs, and skin. ${ }^{25}$ Thus, we speculated that MLN-DCs of $\mathrm{VA}(-)$ mice $(\mathrm{VA}(-) \mathrm{MLN}-\mathrm{DCs})$ may participate in the induction of oral antigen-specific inflammatory or allergic responses in an IL-13-dependent manner. Indeed, VA( - ) mice that received repeated oral antigen administration exhibited IL-13-dependent strong IgG1 responses and subsequent IgE responses upon antigen challenge with an adjuvant. We suggest that RA plays a critical role in the inhibition of inflammatory or allergic responses to oral antigens partly by preventing MLN-DCs from inducing IL-13-producing inflammatory Th2 cells.

\section{RESULTS}

MLN-DCs of VA( - ) mice efficiently induce IL-13-producing inflammatory Th2 cells and Th17 cells

We first evaluated the ability of DCs obtained from various lymphoid organs of $\mathrm{VA}(-)$ and $\mathrm{VA}(+)$ mice to induce functional naive $\mathrm{CD} 4{ }^{+}$T-cell differentiation. $\mathrm{VA}(-) \mathrm{MLN}$ DCs induced $T$ cells to express markedly higher levels of $\mathrm{E}$ - and P-selectin ligands, Ccr2, Ccr4, Ccr5, and Ccr6, but lower levels of Ccr9 compared with VA(+)MLN-DCs (Figure 1a-c). The proteins encoded by these genes are involved in $\mathrm{T}$-cell homing to inflammatory sites or the skin. ${ }^{31}$ Indeed, T cells activated with VA( -$)$ MLN-DCs preferentially migrated into inflamed skin (Figure 1d). In the presence of TGF- $\beta, \mathrm{VA}(+) \mathrm{MLN}-\mathrm{DCs}$ induced the expression of Foxp3 and CD103 on T cells, whereas $\mathrm{VA}(-) \mathrm{MLN}-\mathrm{DCs}$ induced the weak expression of these molecules (Figure 1e). VA deficiency had a much lesser impact on the ability of DCs from other lymphoid organs to induce $\mathrm{T}$ cells to express these molecules, except for splenic (SPL)-DCs, and induce Ccr4 expression (Figure 1a,b).

$\mathrm{T}$ cells induced by $\mathrm{VA}(-) \mathrm{MLN}-\mathrm{DC}$ s produced higher levels of IL-4, IL-9, IL-13, IL-17A, IL-21, and TNF- $\alpha$ upon activation than those induced by VA(+)MLN-DCs (Figure 2a). In particular, IL-13 and TNF- $\alpha$ levels were strikingly higher. Most of the IL-13-producing T cells expressed TNF- $\alpha$ but not interferon- $\gamma$ (IFN- $\gamma$ ) or IL-17A (Figure 2b), suggesting that these $\mathrm{T}$ cells were inflammatory Th2 cells. However, they produced low levels of IL-5 unlike previously described inflammatory Th2 cells (Figure 2a). ${ }^{32}$ Thus, these IL-13producing $\mathrm{T}$ cells appear to be a distinct subset of inflammatory Th2 cells. On the other hand, T cells induced by DCs from Peyer's patches (PPs) of VA( - ) or VA $(+)$ mice produced low levels of cytokines except for IFN- $\gamma$ (Figure 2a). T cells induced by DCs from the skin-draining peripheral lymph nodes (PLNs) of VA( - ) mice produced significantly higher levels of IL-17A, IL-21, and TNF- $\alpha$, and lower levels of IFN- $\gamma$, IL-4, and IL-10 than those induced by VA( + PLN-DCs. T cells induced by VA( - )SPL-DCs produced higher levels of IFN- $\gamma$ and IL-10 than those induced by VA(+)SPL-DCs, but their production levels of other cytokines were low. These results suggest that VA deficiency facilitates PLN-DCs to induce Th17 cells, but most strikingly affects the nature of MLN-DCs and causes them to induce IL-13-producing inflammatory Th2 and Th17 cells that express homing receptors for inflammatory sites or the skin.

\section{VA deficiency enhances inflammatory signatures in conventional DCs (cDCs) of MLNs}

VA( - )MLN-DCs expressed higher levels of Il6, Il12b (encodes IL-12p40), and Tnfsf4 (encodes OX40L), but lower levels of Il10, Tgfbl, and $M m p 9$ (encoding matrix metallopeptidase 9 that activates TGF- $\beta$ ) compared with VA(+)MLN-DCs (Figure 3a). Thus, VA $(-)$ MLN-DCs may have a predominant inflammatory nature.

B220 ${ }^{-}$cDCs from VA( - )MLNs expressed higher levels of CD40, CD86, and major histocompatibility complex class II, but lower levels of CD103 than those from VA(+)MLNs (Figure 3b). On the other hand, VA deficiency did not significantly affect the surface marker expression on PP-cDCs or $\mathrm{B}_{22}{ }^{+}$plasmacytoid DCs (pDCs) of MLNs (Supplementary Figure S1 online). In PP-pDCs, however, VA deficiency increased the proportion of $\mathrm{CCR} 9^{+} \mathrm{CD} 8 \alpha^{+} \mathrm{CD} 40^{-}$ $\mathrm{CD} 80^{-} \mathrm{CD} 86^{-}$major histocompatibility complex class $\mathrm{II}^{\text {low }}$ cells (Supplementary Figure S1b), the phenotype of which resembled that of tolerogenic CCR ${ }^{+}$pDCs. ${ }^{33}$ The VA status did not significantly affect surface marker expression on SPL-DCs and PLN-DCs (data not shown). These results collectively suggest that VA deficiency increases the proportion of inflammatory mature or activated cells in the MLN-cDC population.

\section{The CD8 $\alpha^{-} \mathrm{CD}_{11 b}{ }^{+} \mathrm{CD}_{103}{ }^{-} \mathrm{cDC}$ subset of MLNs in $\mathrm{VA}(-)$ mice instructs naive $\mathrm{CD} 4^{+} \mathrm{T}$ cells to differentiate into IL-13-producing inflammatory Th2 cells in an IL-6-dependent manner}

To identify the DC subset responsible for IL-13-producing inflammatory Th2 induction, we fractionated VA( -$)$ MLNDCs (Figure 3c). VA deficiency most strikingly affected surface marker expression in the $\mathrm{CD} 8 \alpha^{-} \mathrm{CD} 11 \mathrm{~b}^{+} \mathrm{CD} 103^{-} \mathrm{CDC}(\mathrm{R} 2)$ 
a
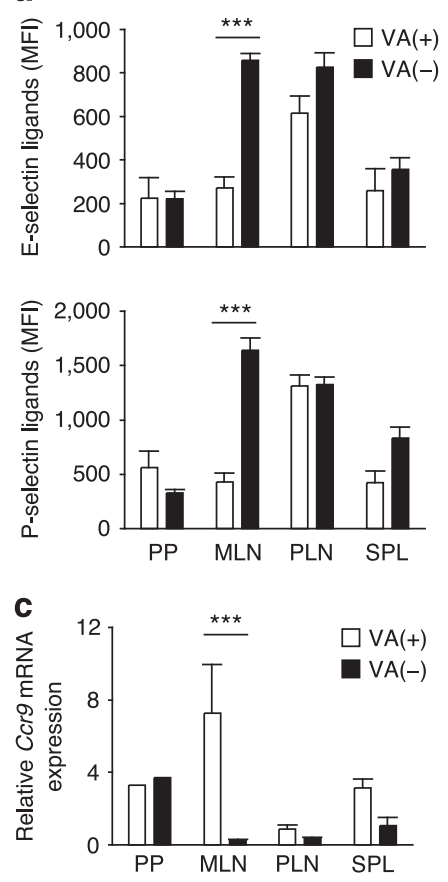

b
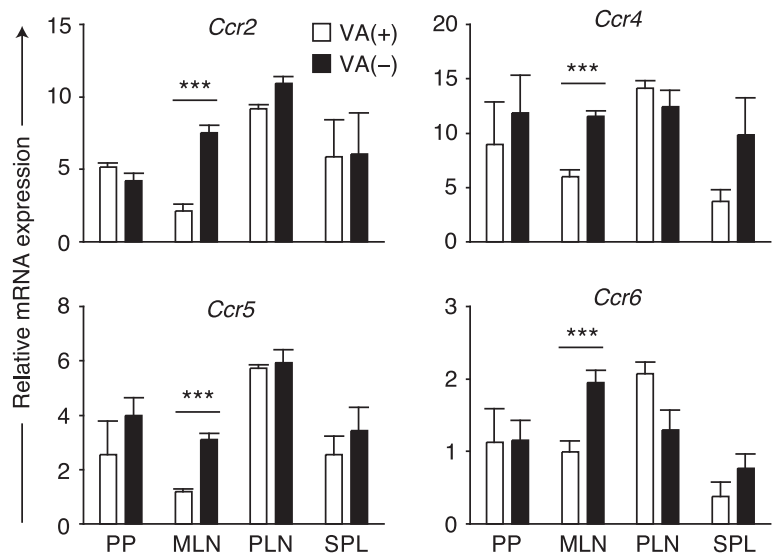

d
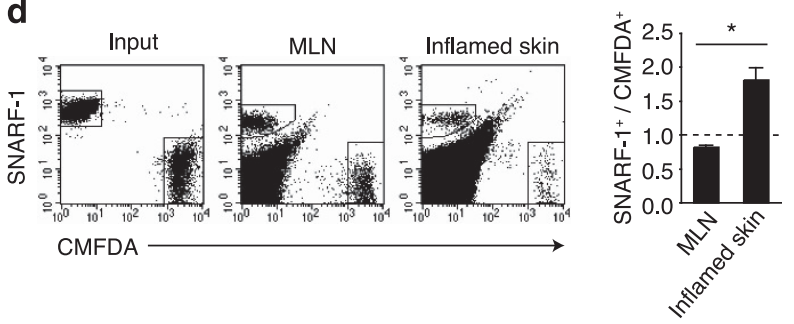
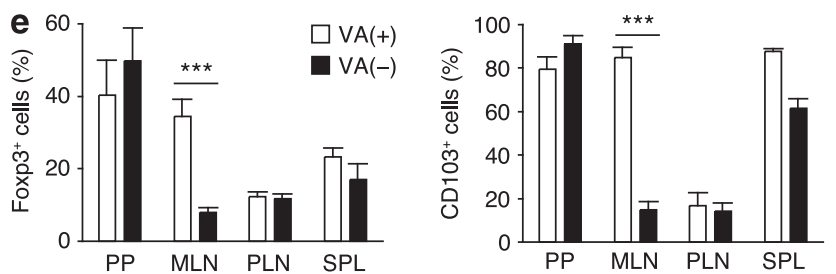

Figure 1 Dendritic cells (DCs) from mesenteric lymph nodes (MLNs) of vitamin A-deficient (VA $(-)$ ) mice instruct T cells to express homing receptors for inflammatory sites or skin. (a) CD4 ${ }^{+} \mathrm{T}$ cells from DO11.10/Rag2 ${ }^{-1-}$ mice were stimulated with ovalbumin (OVA) peptide and DCs from Peyer's patches (PPs), MLNs, peripheral lymph nodes (PLNs), or spleens (SPLs) of VA $(+)$ or VA( - ) mice. Expression of E-and P-selectin ligands on the T cells was analyzed by flow cytometry. Data are expressed as mean fluorescence intensities (MFIs). (b) mRNA expression of chemokine receptors in CD4 ${ }^{+}$

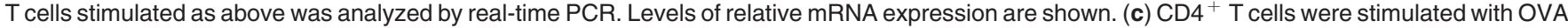
peptide-pulsed DCs from the indicated tissue of VA $(+)$ or VA $(-)$ mice. Relative Ccr9 mRNA expression in the T cells is shown. (d) CD4 ${ }^{+} \mathrm{T}$ cells were stimulated with MLN-DCs from $\mathrm{VA}(+)$ or $\mathrm{VA}(-)$ mice as in $\mathbf{a}$, and were differentially labeled with 5-chloromethylfluorescein diacetate (CMFDA) and SNARF $^{\circledR}-1$ carboxylic acid acetate succinimidyl ester (SNARF-1). Equal cell numbers of each preparation were mixed and injected intravenously into recipient mice with preexisting cutaneous inflammation in ears induced by 2,4-dinitro-1-fluorobenzene-induced delayed hypersensitivity. After $16 \mathrm{~h}$, the transferred cells were recovered from recipient tissues and analyzed by flow cytometry. Representative flow cytometry dot plots are shown. The ratios of SNARF $-1^{+}$cells/CMFDA ${ }^{+}$cells from MLNs and both ears (inflamed skin) are shown as mean + s.e.m., $n=4$ recipient mice. ${ }^{*} P<0.05$. (e) Flow cytometric analysis of forkhead box P3 (Foxp3) and CD103 expression in CD4 ${ }^{+}$T cells stimulated with OVA peptide and the indicated DCs in the presence of transforming growth factor- $\beta$. Data are presented as mean + s.d. of quadruplicate samples. Representative results from three independent experiments are shown. ${ }^{* \star \star} P<0.001$.

subset (Figure 3d). The R2 subset expressed $I l 6, I l 12 b$, and Tnfsf4, but only low levels of Il12a (encodes IL-12p35) and Il23a (encodes IL-23p19) (Figure 3e). VA deficiency especially enhanced the expression of Il6, Ill2b, and Tnfsf4. IL-13producing cells were induced most strongly by $\mathrm{R} 2$, moderately by the $\mathrm{CD} 8 \alpha^{-} \mathrm{CD} 11 \mathrm{~b}^{+} \mathrm{CD} 103^{+} \mathrm{cDC}(\mathrm{R} 3)$ subset, and weakly by the other $\mathrm{CDC}$ subsets (Figure 4a). However, IL-17Aproducing cells were induced most strongly by R3 and slightly less strongly by R2. Both R2 and R3 induced TNF- $\alpha$-producing cells. IFN- $\gamma$-producing cells were most efficiently induced by the $\mathrm{CD} 8 \alpha^{+} \mathrm{CD} 11 \mathrm{~b}^{-} \mathrm{cDC}(\mathrm{R} 1)$ subset and less efficiently by R2 (Figure 4a). T cells stimulated with R2 or R3 expressed Ccr2, Ccr4, Ccr5, and Ccr6 (Supplementary Figure S2a) and high levels of E- and P-selectin ligands (Supplementary Figure S2b). The results suggest that R2 and R3 most efficiently induce IL-13-producing inflammatory Th2 and Th17, respectively, and that these $\mathrm{T}$ cells are tropic to the skin or inflammatory sites.

We then analyzed the mechanism of IL-13-producing inflammatory Th2 induction by R2. An IL-6-neutralizing antibody inhibited the induction of IL-13-, IL-17A-, or TNF- $\alpha$ producing $\mathrm{T}$ cells (Figure $\mathbf{4 b}$ ). Neutralizing antibodies against IL-12p40 and IL-23p19 suppressed the induction of IL-13producing cells but not of IL-17A-producing cells. The results suggest that IL- 6 and monomeric IL-12p40 or its homodimer IL-12p80 participate in IL-13-producing inflammatory Th2 

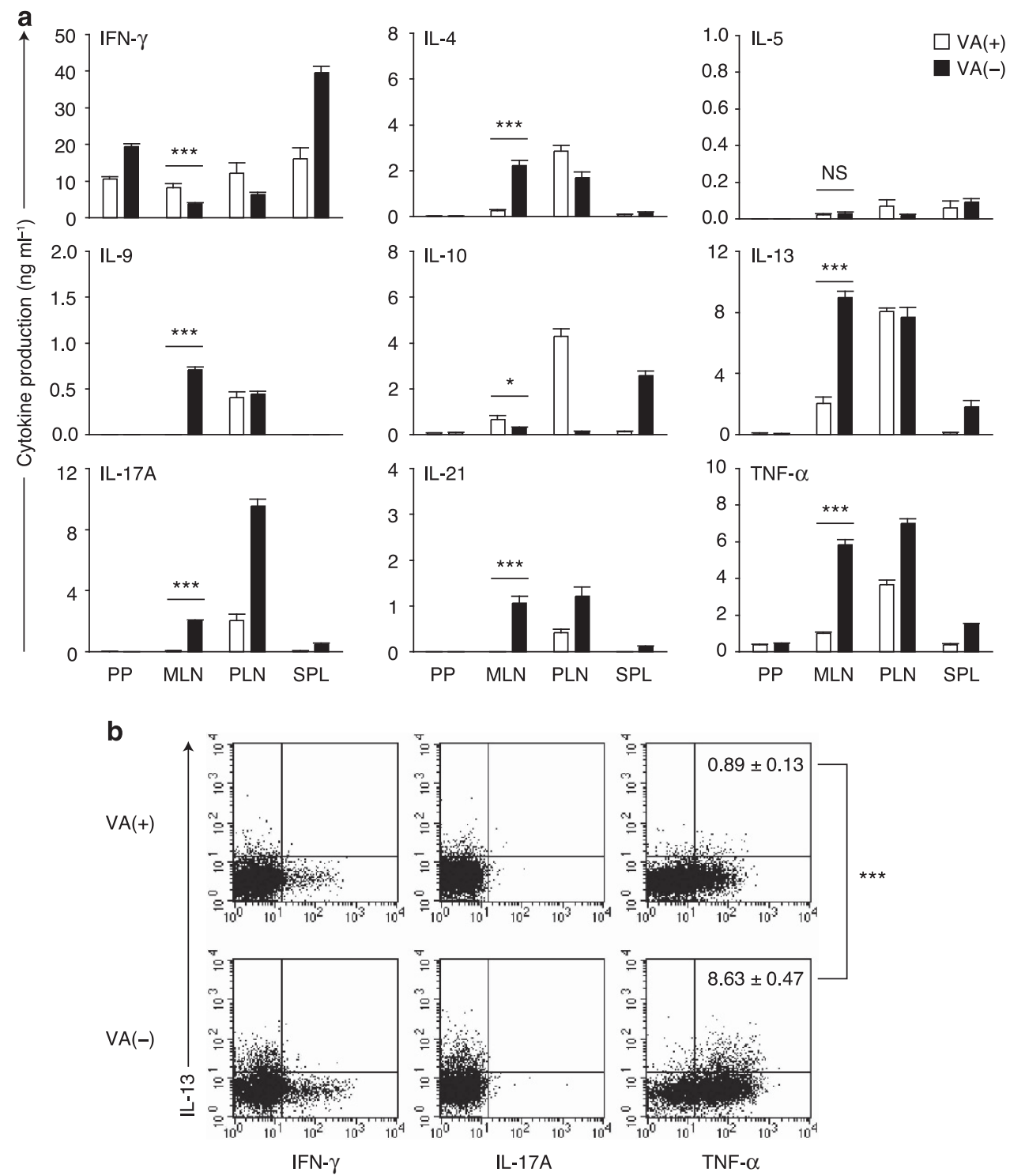

Figure 2 Dendritic cells (DCs) from mesenteric lymph nodes (MLNs) of vitamin A-deficient $(\mathrm{VA}(-))$ mice instruct $\mathrm{T}$ cells to differentiate into interleukin-13 (IL-13)-producing inflammatory Thelper type 2(Th2) cells. (a) CD4 ${ }^{+}$T cells from DO11.10/Rag2 ${ }^{-1-}$ mice were stimulated with ovalbumin (OVA) peptide and DCs from Peyer's patches (PPs), MLNs, peripheral lymph nodes (PLNs), or spleens (SPLs) of VA $(+)$ or VA $(-)$ mice, and were restimulated with immobilized monoclonal antibodies to CD3 and CD28. Cytokine concentrations in the supernatants were assessed by enzyme-linked immunosorbent assay. Data are presented as mean + s.d. of quadruplicate samples. ${ }^{\star} P<0.05$; ${ }^{* * *} P<0.001$; NS, not significant. Representative results from three independent experiments are shown. IFN- $\gamma$, interferon- $\gamma$. (b) CD4 ${ }^{+}$T cells were stimulated with OVA peptide and MLN-DCs from $\mathrm{VA}(+)$ or $\mathrm{VA}(-)$ mice, and were restimulated with immobilized anti-CD3 and soluble anti-CD28 in the presence of monensin. Representative flow cytometry dot plots (from three independent experiments) of intracellular cytokine expression are shown. The percentage of IL-13 ${ }^{+}$tumor necrosis factor (TNF)- $\alpha^{+}$cells is shown as mean \pm s.d. of quadruplicate samples. ${ }^{* \star \star} P<0.001$.

induction and that IL- 6 but not IL-12p40 is required for Th17 induction. The balance between the IL-13-producing inflammatory Th2 and Th17 subsets in T cells stimulated with $\mathrm{VA}(-) \mathrm{MLN}-\mathrm{cDCs}$ slightly varied according to the experiments. OX40L expression on DCs is known to contribute to the induction of inflammatory Th2 cells. ${ }^{32}$ An OX40L-blocking antibody partly inhibited the ability of R2 to induce IL-13-producing $\mathrm{T}$ cells, but enhanced its ability to induce IL-17A-producing $\mathrm{T}$ cells (Figure $4 \mathbf{b}$ ). These results suggest that IL- 6 is essential for the induction of both IL-13-producing inflammatory Th2 and Th17 cells, and that OX40L-mediated signals affect the IL-13-producing inflammatory Th2/Th17 balance.

\section{RA receptor (RAR)-mediated signals prevent MLN-DCs from inducing IL-13-producing inflammatory Th2 differentiation}

RAR-mediated signals can contribute to DC homeostasis in an autocrine or paracrine manner in the MLNs of normal and $\mathrm{VA}(+)$ mice. Indeed, RA prevented $\mathrm{VA}(-) \mathrm{MLN}-\mathrm{DC}$ from 


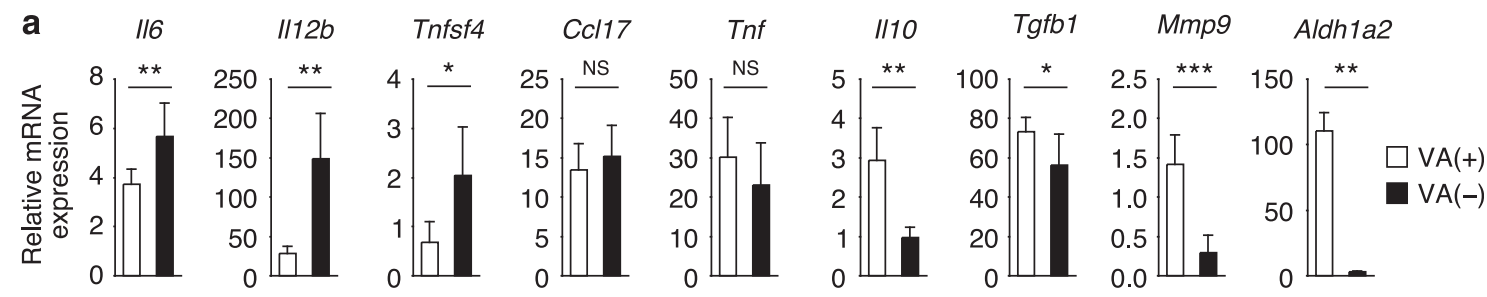

b
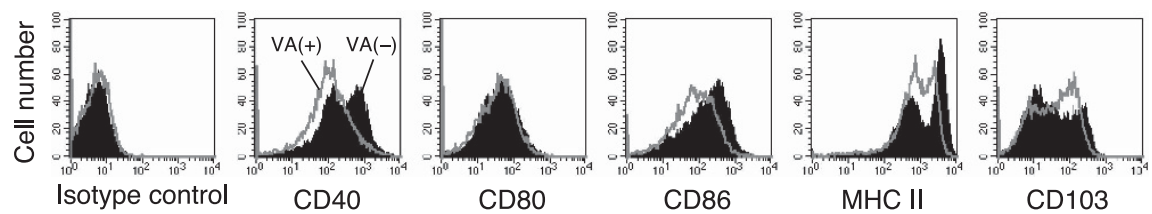

Isotype control

CD40

CD80

$\mathrm{MHC}$ II

CD103

c

$\operatorname{VA}(+)$
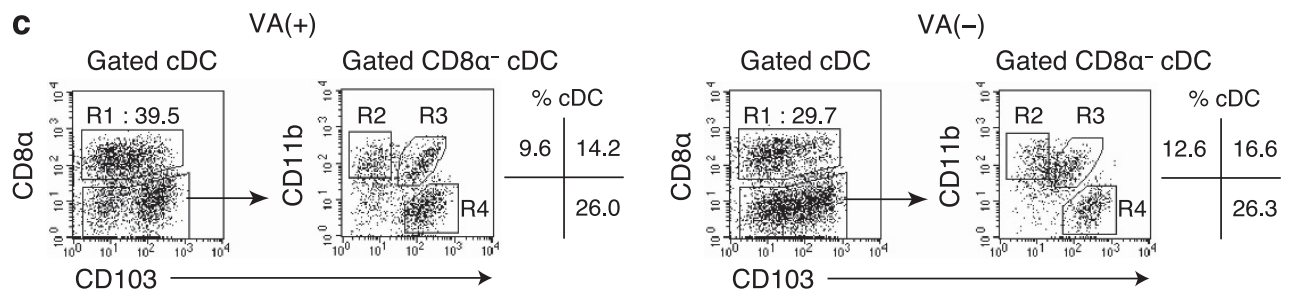

d

R
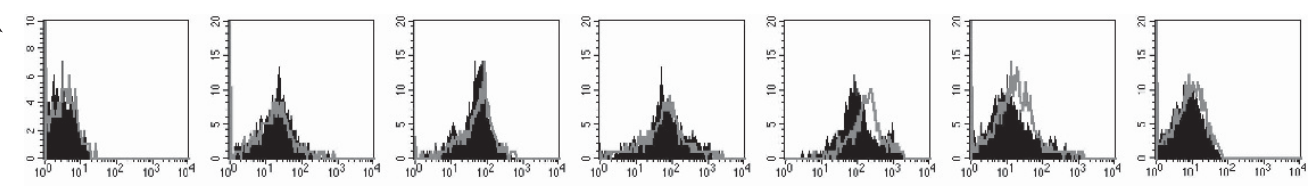

$\mathrm{R} 2$
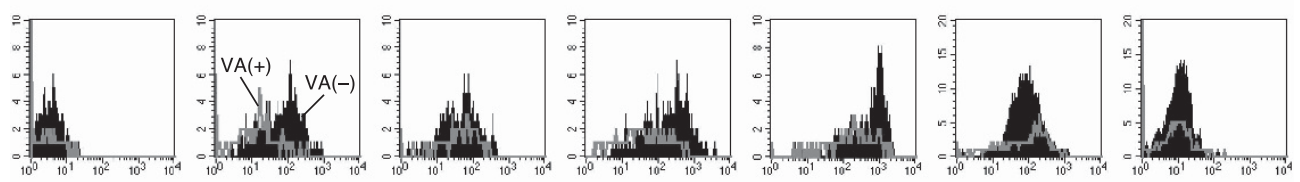

R3
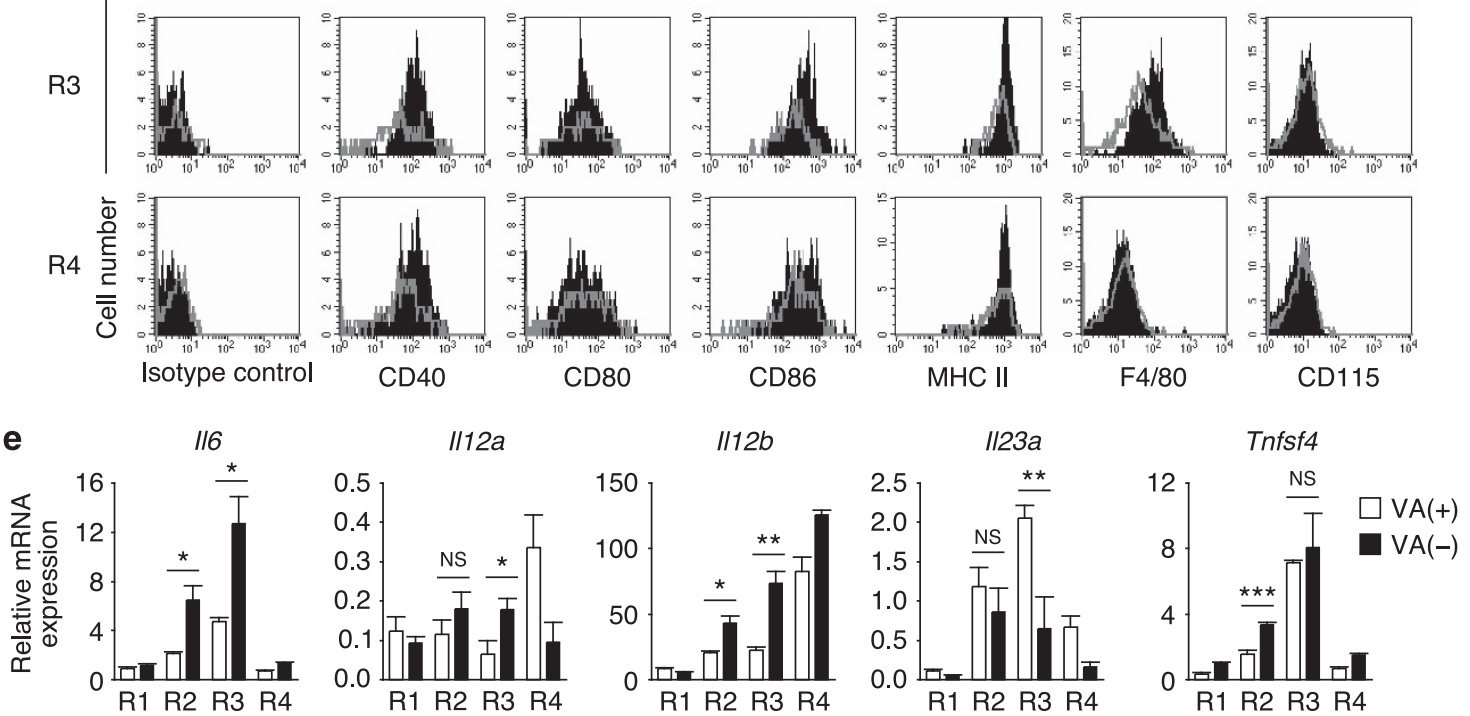

Figure 3 The $\mathrm{CD} 8 \alpha^{-} \mathrm{CD} 11 \mathrm{~b}^{+} \mathrm{CD}_{103^{-}}$subset of conventional dendritic cells (cDCs) from mesenteric lymph nodes (MLNs) of vitamin A-deficient $(\mathrm{VA}(-))$ mice exhibits more inflammatory phenotypes than VA(+)MLN-DCs. (a) Relative mRNA expression of indicated genes in total CD11c ${ }^{+}$ cells from MLNs of $\mathrm{VA}(+)$ and $\mathrm{VA}(-)$ mice. Data are presented as mean + s.d. of triplicate samples. Representative results from three independent experiments are shown. ${ }^{\star} P<0.05 ;{ }^{* \star} P<0.01 ;{ }^{* \star \star} P<0.001$; NS, not significant. (b) Representative flow cytometry histograms (from three independent experiments) of the expression of the indicated molecules on gated B220 ${ }^{-} \mathrm{CD} 11 \mathrm{c}^{+} \mathrm{cDCs}$ from MLNs of VA $(+)($ solid line $)$ and VA $(-)$ mice (shaded histogram). (c) Scheme for sorting MLN-DC subsets from VA $(+)$ and VA $(-)$ mice. Left dot plots show division of $B 220^{-} C^{-} 11 c^{+} \mathrm{cDCs}$ into two major CD8 $\alpha^{+}$(R1) and CD8 $\alpha^{-}$subsets. CD8 $\alpha^{-}$cDCs were further subdivided into CD11b ${ }^{+} \mathrm{CD}_{103}{ }^{-}$(R2), $\mathrm{CD} 11 \mathrm{~b}^{+} \mathrm{CD} 103^{+}(\mathrm{R} 3), \mathrm{and}$ $\mathrm{CD}_{11 b^{-}} \mathrm{CD}_{103}{ }^{+}$(R4) subsets. (d) Representative flow cytometry histograms (from three independent experiments) of the surface expression of the indicated molecules on MLN-DC subsets from VA(+) (solid line) and $\mathrm{VA}(-)$ mice (shaded histogram). (e) Relative mRNA expression of the indicated molecules in MLN-DC subsets from VA(+) and $\mathrm{VA}(-)$ mice. Data are presented as mean + s.d. of triplicate samples. Representative results from three independent experiments are shown. 
inducing $\mathrm{T}$ cells that produced high levels of IL-13, IL-17A, TNF- $\alpha$, or IFN- $\gamma$ (Figure 5a). However, the RAR antagonists LE135 or LE540 enhanced the ability of MLN-DCs of normal mice to induce IL-13-, IL-17A-, or TNF- $\alpha$-producing T cells (Figure 5b). In the presence of LE135 or LE540, the $\mathrm{CD} 8 \alpha^{-} \mathrm{CD}_{11} \mathrm{~b}^{+} \mathrm{CD}_{103}{ }^{-}$(R2) MLN-cDC subset of normal mice induced $\mathrm{T}$ cells that produced high levels of IL-13, IL-17A, and TNF- $\alpha$ (Figure 5c). IL-17A-producing T cells were also induced by the $\mathrm{CD} 8 \alpha^{-} \mathrm{CD} 11 \mathrm{~b}^{+} \mathrm{CD} 103^{+}$(R3) subset in the presence of LE540, but not by the CD $8 \alpha^{+} \mathrm{CD} 11 b^{-} \mathrm{CD} 103^{-/+}$
(R1) and $\mathrm{CD} 8 \alpha^{-} \mathrm{CD}_{11 \mathrm{~b}}{ }^{-} \mathrm{CD}_{103}{ }^{+}$(R4) subsets. R1 induced IFN- $\gamma$-producing T cells in the presence of LE135. Importantly, each cDC subset was differentially affected by RAR antagonists with regard to the induction of cytokine-producing $\mathrm{T}$ cells. The LE540-dependent normal R2-mediated induction of IL-13-, IL-17A-, and TNF- $\alpha$-producing T-cell subsets was abrogated by a neutralizing antibody against IL- 6 and partly abrogated by an antibody against IL-12p40 (Figure 5d). A blocking antibody against OX40L partly inhibited the induction of IL-13- and TNF- $\alpha$-producing T cells but not of IL-17A-producing T cells.

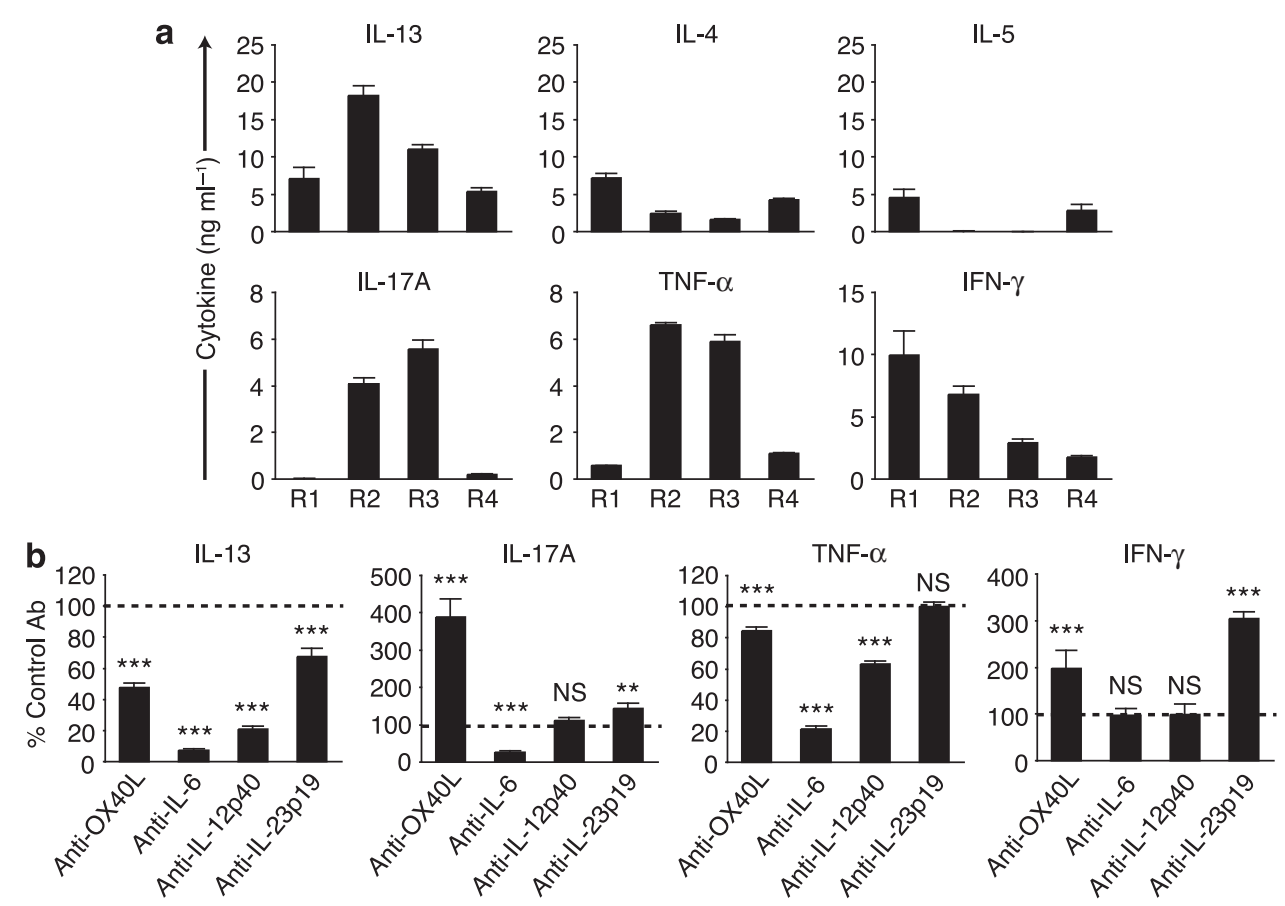

Figure 4 The CD8 $\alpha^{-} \mathrm{CD} 11 b^{+} \mathrm{CD}_{103}{ }^{-}$subset of conventional dendritic cells (cDCs) from mesenteric lymph nodes (MLNs) of vitamin A-deficient (VA(-)) mice most efficiently induces interleukin-13 (IL-13)-producing inflammatory T helper type 2 (Th2) differentiation. (a) CD4 ${ }^{+} \mathrm{T}^{2}$ cells from DO11.10/Rag2 ${ }^{-l-}$ mice were stimulated with ovalbumin (OVA) peptide and MLN-DC subsets (R1, CD8 $\alpha^{+}$CD11b ${ }^{-}$CD103 $3^{+l-}$ cDCs;

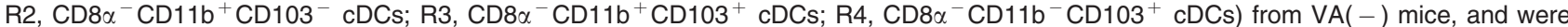
restimulated with immobilized monoclonal antibodies (mAbs) to CD3 and CD28. Cytokine concentrations in the supernatants were assessed by enzyme-linked immunosorbent assay (ELISA). (b) CD4 ${ }^{+} \mathrm{T}$ cells were stimulated with OVA peptide and CD8 $\alpha^{-} \mathrm{CD} 11 \mathrm{~b}^{+} \mathrm{CD} 103^{-}$(R2) subset of MLN-cDCs from VA( - ) mice in the presence of anti-OX40L, anti-IL-6, anti-IL-12p40, anti-IL-23p19, or isotype control mAbs, and were restimulated with immobilized mAbs to CD3 and CD28. Cytokine concentrations in the supernatants were assessed by ELISA. Results are shown as the percentage of the control culture with the isotype control mAb. Data are presented as mean + s.d. of quadruplicate. ${ }^{* \star} P<0.01 ;{ }^{* \star *} P<0.001$; NS, not significant vs. control mAb. Representative results from three independent experiments are shown.

Figure 5 Retinoic acid receptor (RAR)-mediated signals prevent dendritic cells (DCs) of mesenteric lymph nodes (MLNs) from inducing interleukin-13 (IL-13)-producing inflammatory T helper type 2 (Th2) differentiation. (a) CD4 ${ }^{+}$T cells from DO11.10/Rag2 ${ }^{-/}$mice were stimulated with ovalbumin (OVA) peptide and MLN-DCs from vitamin A-deficient $(\mathrm{VA}(-))$ or VA $(+)$ mice in the presence or absence of RA, and restimulated with immobilized monoclonal antibodies (mAbs) to CD3 and CD28. Cytokine concentrations in the supernatants were assessed by enzyme-linked immunosorbent assay (ELISA). ${ }^{*} P<0.05 ;{ }^{* *} P<0.01 ;{ }^{* * *} P<0.001$; NS, not significant. (b) CD4 ${ }^{+} \mathrm{T}$ cells were stimulated with OVA peptide and (b) whole

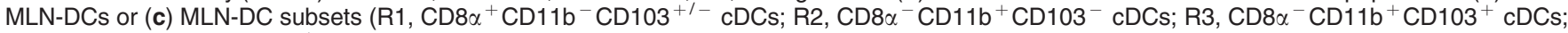
$\mathrm{R} 4, \mathrm{CD} 8 \alpha^{-} \mathrm{CD} 11 \mathrm{~b}^{-} \mathrm{CD}_{103}{ }^{+} \mathrm{CDCs}$ ) of normal mice in the presence or absence of LE135 or LE540, and were restimulated with immobilized mAbs to CD3 and CD28. Cytokine concentrations in the supernatants were assessed by ELISA. ${ }^{*} P<0.05 ;{ }^{* \star} P<0.01 ;{ }^{* \star *} P<0.001$ vs. absence of LE135 and LE540. (d) CD4 ${ }^{+}$T cells were stimulated with OVA peptide, LE540, and the CD8 $\alpha^{-}$CD11b ${ }^{+}$CD103 ${ }^{-}$(R2) subset of MLN-cDCs from normal mice in the presence of anti-OX40L, anti-IL-6, anti-IL-12p40, or isotype control mAbs, and were restimulated with immobilized mAbs to CD3 and CD28. Cytokine concentrations in the supernatants were assessed by ELISA. Results are shown as the percentage of the control culture with the isotype control mAb. ${ }^{\star} P<0.05$; ${ }^{\star \star} P<0.01$; ${ }^{\star \star \star} P<0.001$; NS, not significant vs. control mAb. Data are presented as mean + s.d. of quadruplicate samples. Representative results from three independent experiments are shown. 
These results suggest that in normal mice, MLN-DCs possess the latent ability to induce IL-13-producing inflammatory Th2 and Th17 cell differentiation, and that RA prevents the differentiation of these $\mathrm{T}$ cells by modulating the nature of MLN-cDCs, especially R2 and R3.

\section{IL-6 instructs naive T cells to differentiate into IL-13-producing inflammatory Th2 cells}

We examined whether IL- 6 and other molecules could directly induce IL-13-producing inflammatory Th2 differentiation. In a DC-free culture system, naive $\mathrm{CD} 4{ }^{+} \mathrm{T}$ cells that were a

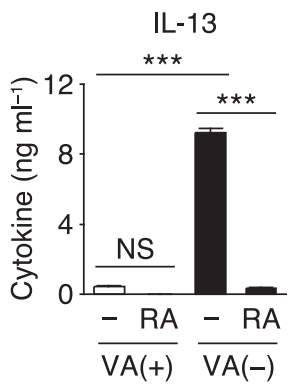

IL-17A

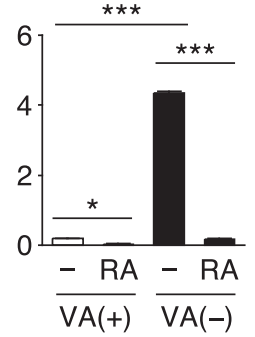

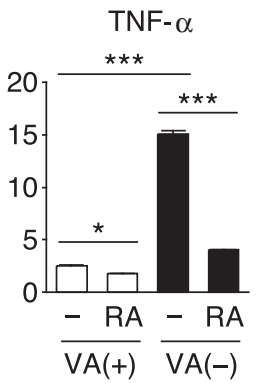

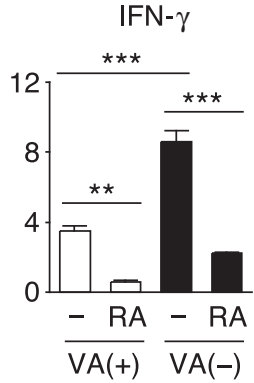

b

IL-13

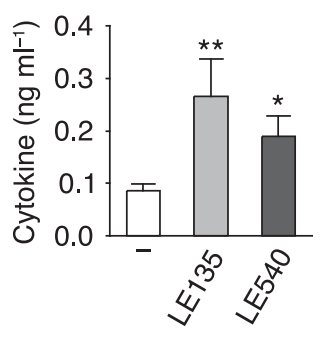

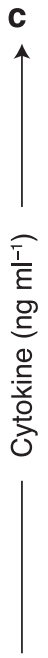

d

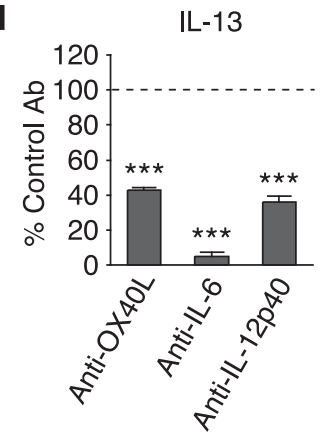

IL-17A

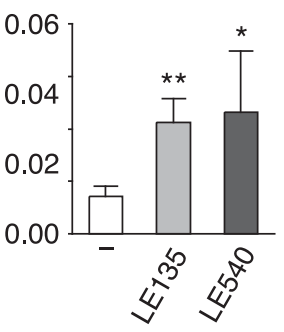

IFN- $\gamma$
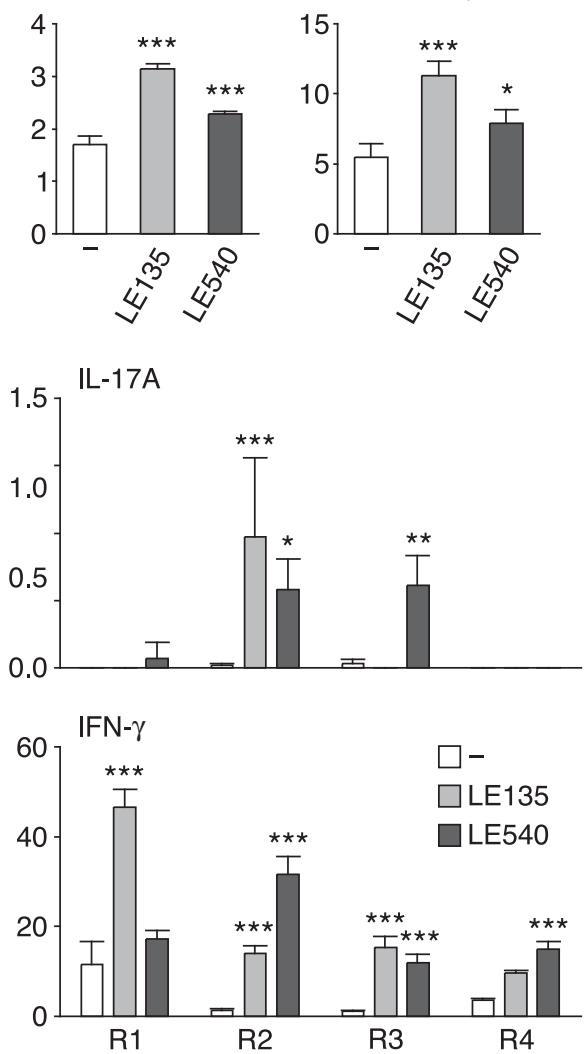

TNF- $\alpha$

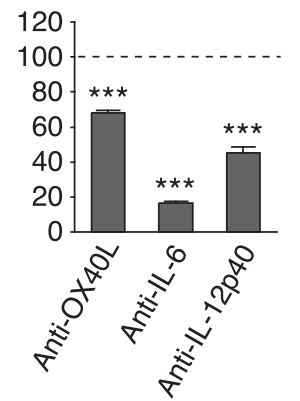

IFN- $\gamma$

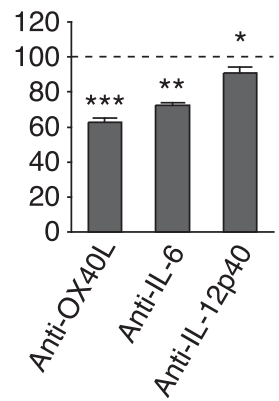

Figure 5 For caption please refer page 791. 

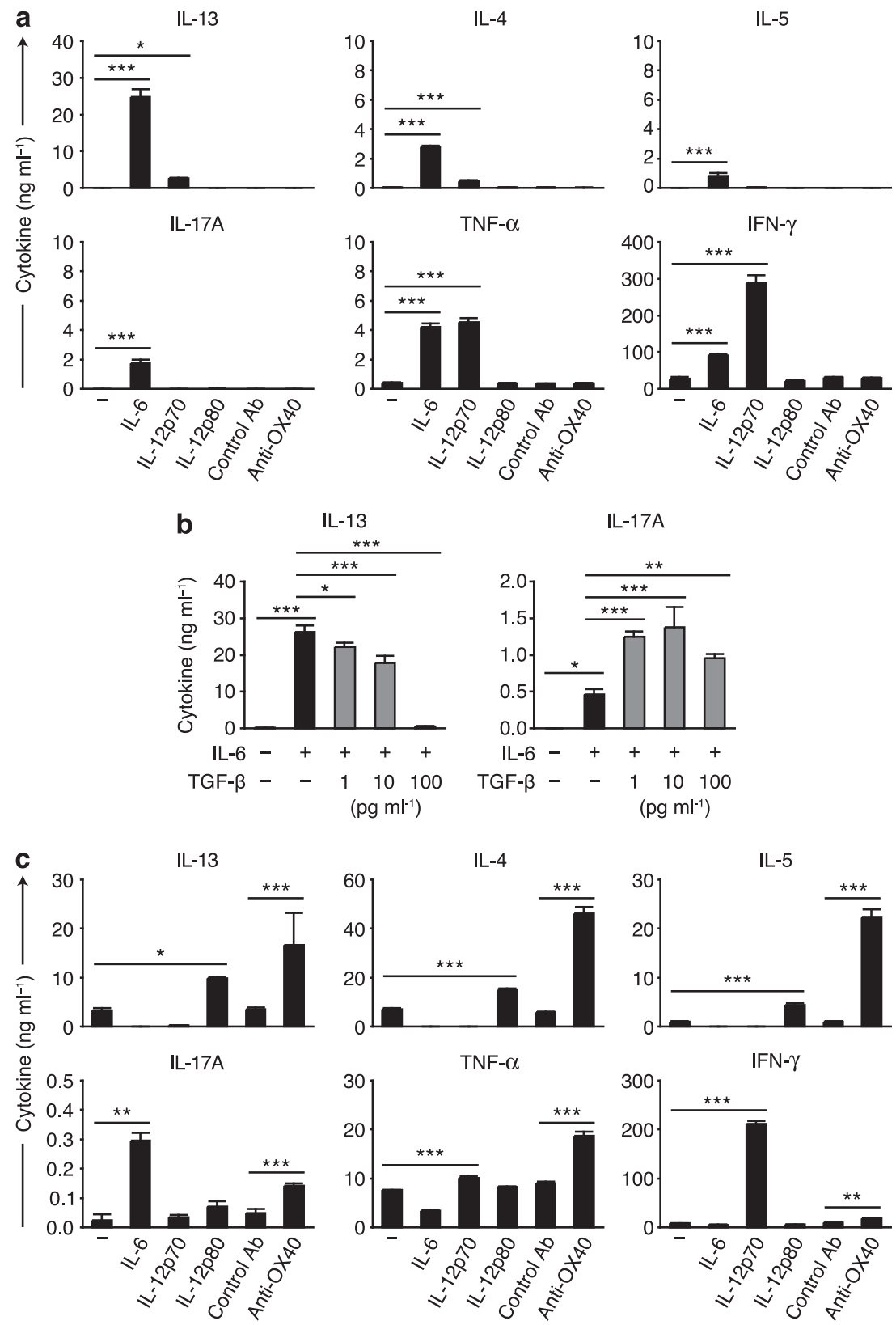

Figure 6 Interleukin-6 (IL-6) instructs naive T cells to differentiate into IL-13-producing inflammatory T helper type 2 (Th2) cells. CD4 ${ }^{+}$T cells from BALB/c mice were stimulated with immobilized monoclonal antibodies (mAbs) to CD3 and CD28 in the presence or absence of (a) IL-6, IL-12p70, IL-12p80 (10 $\left.\mathrm{ng} \mathrm{ml}^{-1}\right)$, immobilized agonistic anti-OX40 or Rat IgG1 isotype control mAbs $\left(10 \mu \mathrm{g} \mathrm{ml}^{-1}\right)$, or (b) IL-6 and/or transforming growth factor- $\beta$ (TGF- $\beta)$. The cells were restimulated with immobilized mAbs to CD3 and CD28, and cytokine concentrations in the supernatants were assessed by enzyme-linked immunosorbent assay (ELISA). (c) CD4 ${ }^{+} \mathrm{T}$ cells from DO11.10/Rag2 ${ }^{-1-}$ mice were stimulated with ovalbumin peptide and dendritic cells of mesenteric lymph nodes (MLNs) from normal mice in the presence or absence of IL-6, IL-12p70, IL-12p80 (10 ng ml $\left.{ }^{-1}\right)$, soluble anti-OX40, or Rat IgG1 isotype control mAbs $\left(10 \mu \mathrm{g} \mathrm{ml}^{-1}\right)$, and were restimulated with immobilized mAbs to CD3 and CD28. Cytokine concentrations in the supernatants were assessed ELISA. Data are presented as mean + s.d. of triplicate samples. ${ }^{*} P<0.05 ;{ }^{\star \star} P<0.01 ;{ }^{\star \star \star} P<0.001$. Similar results were obtained from three independent experiments.

stimulated with antibodies against $\mathrm{CD} 3$ and $\mathrm{CD} 28$ in the presence of IL-6 differentiated into T cells that produced high levels of IL-13 and TNF- $\alpha$, and lower levels of IL-17A, IL-4, and IL-5 (Figure 6a). IL-6 also enhanced the induction of IFN- $\gamma$ producing $\mathrm{T}$ cells but was much less efficient than IL-12p70. On the other hand, TGF- $\beta$ inhibited the IL- 6 -dependent induction of IL-13-producing $\mathrm{T}$ cells, but reciprocally enhanced the induction of IL-17A-producing T cells (Figure 6b). Similar results were obtained with naive $\mathrm{CD} 4^{+} \mathrm{T}$ cells of $\mathrm{C} 57 \mathrm{BL} / 6$ mice (Supplementary Figure S3). A plate-bound agonistic anti-OX40 antibody failed to affect T-cell cytokine production. However, the anti-OX40 antibody facilitated normal MLN-DCs to induce T cells that produced high levels of IL-4, IL-5, IL-13, and TNF- $\alpha$ (Figure 6c). IL-12p80 moderately 
facilitated MLN-DCs to induce Th2 cells. However, the addition of IL-6 rather suppressed the induction of IL-13producing $\mathrm{T}$ cells, and enhanced the induction of IL-17Aproducing $\mathrm{T}$ cells. TGF- $\beta$ from MLN-DCs may contribute to this result. These findings collectively suggest that IL-6-dependent signals are essential for the specific induction of IL-13-producing inflammatory Th2 and that TGF- $\beta$ can regulate IL-13-producing inflammatory Th2 induction. On the other hand, OX40-mediated signals and IL-12p80 likely contribute to skew $\mathrm{T}$ cells toward general inflammatory Th2 or Th2-related cell subsets, including IL-13-producing inflammatory Th2.

\section{Proximal colon epithelial cells in VA-deficient mice produce TNF- $\alpha$ that can instruct DCs to express OX40L}

VA deficiency also affects the nature of intestinal epithelial cells, and can direct them to produce inflammatory cytokines that induce OX40L expression in DCs. ${ }^{32,34,35}$ Indeed, VA deficiency markedly enhanced TNF- $\alpha$ expression in proximal colon epithelial cells (Figure 7a,b). As lymph from the proximal colon drains into the MLNs, TNF- $\alpha$ production may affect the nature of MLN-DCs. TNF- $\alpha$ induced the expression of OX40L, CD40, and CD86 in murine fms-related tyrosine kinase 3 ligand (Flt3L)-generated bone marrow (BM)-DCs and the production of low levels of IL-6, and RA partly suppressed this induction except for CD40 and IL-6 (Figure 7c,d). TNF- $\alpha$-treated BMDCs instructed T cells to produce extremely high levels of IL-4, IL-5, and IL-13 in an OX40L-dependent manner (Figure 7e and f). RA partly suppressed this production. Thus, in $\mathrm{VA}(-)$ mice, TNF- $\alpha$ may enhance the ability of MLN-DCs to induce general inflammatory Th2 cells. Accordingly, injections of antiTNF- $\alpha$ antibody into $\mathrm{VA}(-)$ mice for 2 weeks tended to downregulate this ability (data not shown). These results suggest that VA or RA can also regulate the nature of MLN-DCs by suppressing both TNF- $\alpha$ production in the proximal colon and TNF- $\alpha$ signaling in MLN-DCs.

IL-33-expressing cells and thymic stromal lymphopoietinexpressing cells were detected in the MLNs, PPs, small intestine, and proximal colon of unprimed $\mathrm{VA}(-)$ mice as frequently as that in $\mathrm{VA}(+)$ mice. However, VA deficiency increased the number of IL-33-expressing epidermal cells in the ear (data not shown). IL-33, but not thymic stromal lymphopoietin, induced the CD86, IL-6, and low levels of OX40L and CD40 expression in BM-DCs, and RA partly suppressed this induction (Supplementary Figure S4 and data not shown).

\section{VA deficiency increases the risk of strong immune responses to oral antigens}

As MLN-DCs can present oral antigens, we re-examined whether VA deficiency affected oral tolerance, using a classical system of tolerance induction. Mice received repeated intragastric administration of ovalbumin (OVA), followed by challenges of OVA with an adjuvant. In $\mathrm{VA}(+)$ mice, regardless of the route of challenge, repeated OVA administration significantly reduced the OVA-induced proliferation of draining MLN or PLN cells in vitro compared with saline administration (Figure 8a-c). In $\mathrm{VA}(-)$ mice, however, repeated OVA administration did not significantly reduce cell proliferation (Figure 8a-c), except for PLN-cell proliferation when assessed 1 week after the subcutaneous challenge (Figure 8c, left). The latter result agreed with a previous observation under similar conditions. ${ }^{22}$ However, PLN cells obtained from OVA-fed VA( - ) mice 2 weeks after the subcutaneous challenge proliferated equally to those obtained from saline-fed control mice (Figure 8c, right) as reported previously. ${ }^{17}$ Unexpectedly, however, MLN cells obtained from OVA-fed $\mathrm{VA}(-)$ mice 1 week after intraperitoneal (i.p.) challenge exhibited higher proliferation levels than those from saline-fed control mice (Figure 8a). After repeated OVA feeding, CD4 ${ }^{+}$ $\mathrm{T}$ cells from the MLNs and SPLs of $\mathrm{VA}(-)$ mice, but not $\mathrm{VA}(+)$ mice, produced significant levels of IL-13 and IL-17A upon antigenic stimulation (Figure 8d), indicating that antigen feeding can induce antigen-specific IL-13-producing $\mathrm{T}$ cells and IL-17A-producing $\mathrm{T}$ cells in $\mathrm{VA}(-)$ mice.

\section{Repeated oral antigen administration primes strong antibody responses}

In VA $(+)$ mice, OVA feeding suppressed the serum and fecal antibody responses after two i.p. challenges as expected (Figure 9a,b). However, OVA-fed VA(-) mice exhibited aberrantly high serum levels of anti-OVA IgG1 and IgG2a responses (Figure 9a). The total IgG1 and IgG2a concentrations in the sera of these mice reached $6-10 \mathrm{mg} \mathrm{ml}^{-1}$ and 2.0-2.2 $\mathrm{mg} \mathrm{ml}^{-1}$, respectively. The anti-OVA IgA levels in the sera of these mice were also significantly higher than those in OVA-fed VA $(+)$ or saline-fed VA(-) mice. Furthermore, significant anti-OVA IgE responses were induced in OVA-fed $\mathrm{VA}(-)$ mice. In these mice, a single intradermal OVA injection elicited ear swelling that peaked at $\sim 6 \mathrm{~h}$ after the OVA challenge (Figure 9c,d), suggesting that IgE-mediated and mast cell-dependent immediate-type allergic inflammation was induced. Two i.p. challenges, however, spontaneously induced deaths in some $\mathrm{VA}(-)$ mice. Elevated antibody responses in the OVA-fed VA( - ) mice were already observed after the first i.p. challenge (Supplementary Figure S5). These results suggest that repeated oral antigen administration strongly primes $\mathrm{VA}(-)$ mice for antigen-specific antibody responses, especially IgG1 responses, and eventual $\operatorname{IgE}$ responses that cause allergic skin inflammation. In saline-fed control mice, however, VA deficiency suppressed the OVAspecific serum antibody and fecal IgA antibody responses, as expected (Figure 9a,b). Fecal anti-OVA IgG1 antibodies were detected in OVA-fed VA $(-)$ mice (Figure 9b), suggesting that the intestinal mucosal barrier functions were reduced in $\mathrm{VA}(-)$ mice after repeated antigen administration.

\section{IL-13 is essential for anti-OVA IgG1, IgA, and IgE antibody responses in OVA-pre-fed VA( - ) mice}

IL-13 and IL-21 promote IgG1 antibody production, whereas IL-17A and IL-21 promote IgG2a antibody production. ${ }^{36,37}$ Thus, IL-13-producing inflammatory Th2 or Th17 cells may contribute to oral antigen-specific IgG1 and IgG2a antibody responses. To examine the role of IL-13 in antibody responses, sera were obtained from $I l 13^{-I-} \mathrm{VA}(-)$ mice after repeated 

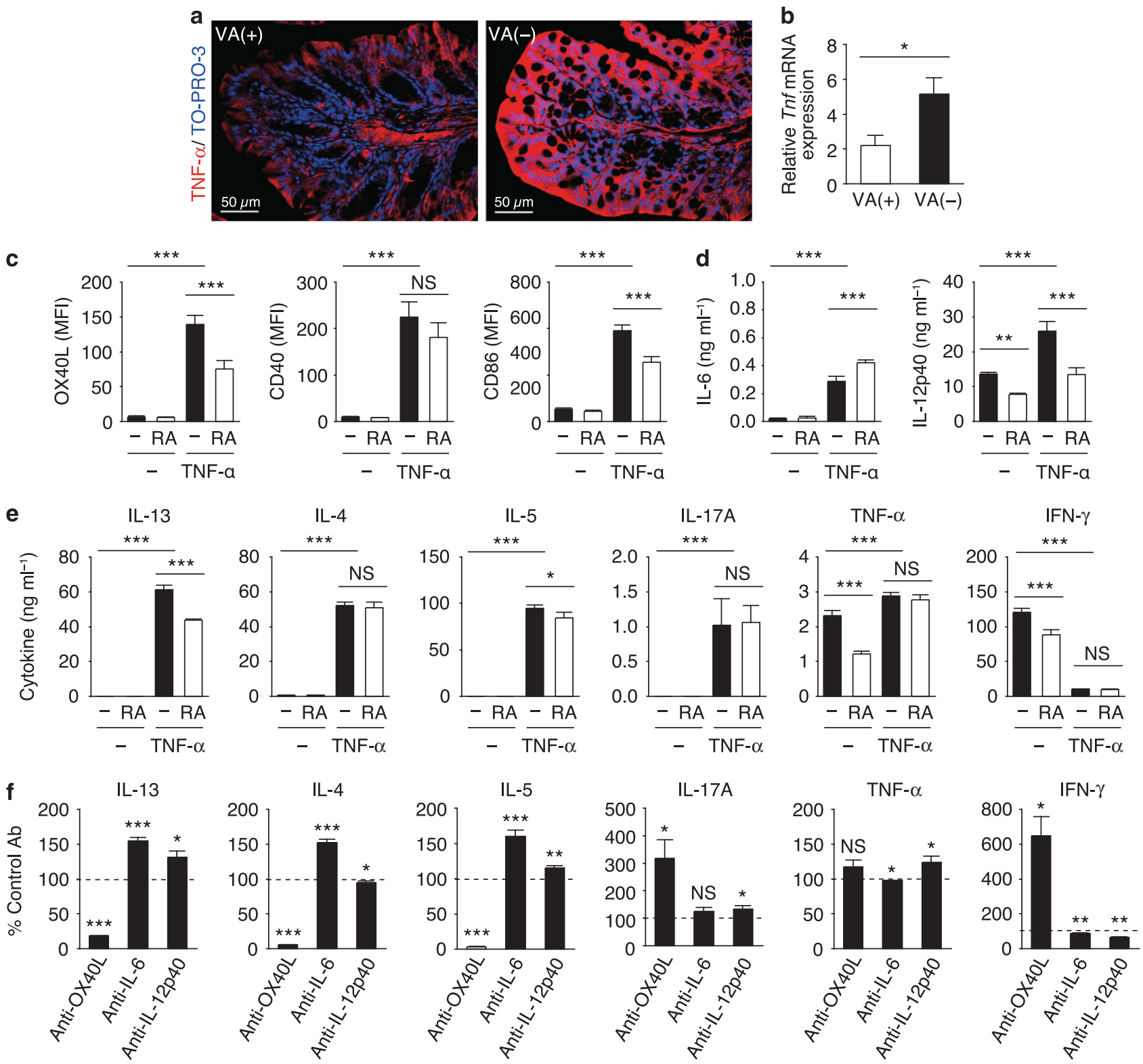

Figure 7 Proximal colon epithelial cells in vitamin (VA)-deficient mice produce tumor necrosis factor- $\alpha$ (TNF- $\alpha$ ) that can instruct bone marrow-derived dendritic cells (BM-DCs) to express OX40L and induce general inflammatory T helper type 2 (Th2) cells. (a) Representative immunofluorescence micrographs of TNF- $\alpha$ expression (red) in proximal colons from VA $(+)$ and VA $(-)$ mice $(n=4$ mice/group). Cell nuclei were visualized with TO-PRO-3 (blue). (b) Relative Tnf mRNA expression in proximal colon epithelial cells from VA $(+)$ and VA $(-)$ mice $(n=5$ mice/group). Data are presented as mean + s.e.m. for each group. ${ }^{*} P<0.05$. (c-e) BM-DCs generated by fms-related tyrosine kinase 3 ligand were treated with TNF- $\alpha$ in the presence or absence of retinoic acid (RA). (c) Expression levels of costimulatory molecules on the treated BM-DCs were analyzed by flow cytometry. Data are expressed as mean fluorescence intensities (MFIs). (d) Cytokine concentrations in the supernatants were assessed by enzyme-linked immunosorbent assay (ELISA). (e) CD4 ${ }^{+}$T cells from DO11.10/Rag2 ${ }^{-1-}$ mice were stimulated with ovalbumin (OVA) peptide and the treated BM-DCs, and were restimulated with immobilized monoclonal antibodies ( $\mathrm{mAbs}$ ) to CD3 and CD28. Cytokine concentrations in the supernatants were assessed by ELISA. (f) $\mathrm{CD}^{+}{ }^{+} \mathrm{T}$ cells were stimulated with OVA peptide and the treated BM-DCs in the presence of anti-OX40L, anti-IL-6, anti-IL-12p40, or isotype control mAbs, and were restimulated with immobilized mAbs to CD3 and CD28. Cytokine concentrations in the supernatants were assessed by ELISA. Results are shown as the percentage of the control culture with the isotype control mAb. ${ }^{\star} P<0.05 ;{ }^{* \star} P<0.01$; ${ }^{* \star \star} P<0.001$; NS, not significant vs. control mAb. Data are presented as mean + s.d. of quadruplicate samples. Representative results from three independent experiments are shown.

OVA administration, followed by oral challenges. The observed anti-OVA IgG1, IgA, and IgE responses were low (Figure 10a). On the other hand, Il13 deficiency did not affect anti-OVA IgG2a responses. Similar results, with stronger responses, were obtained from mice that received i.p. challenges with alum (data not shown). The results suggest that in $\mathrm{VA}(-)$ mice, IL-13 is essential to enhance IgG1, IgA, and IgE responses but not IgG2a responses. OVA prefeeding suppressed the OVA-induced proliferation of MLN cells from VA( + ) and VA( - ) $\mathrm{Ill}^{-1-}$ mice that received intragastric OVA administration and aduvant (Figure 10b), suggesting that IL-13 is not required for the induction of oral tolerance in $\mathrm{T}$ cells of $\mathrm{VA}(+)$ mice, but 

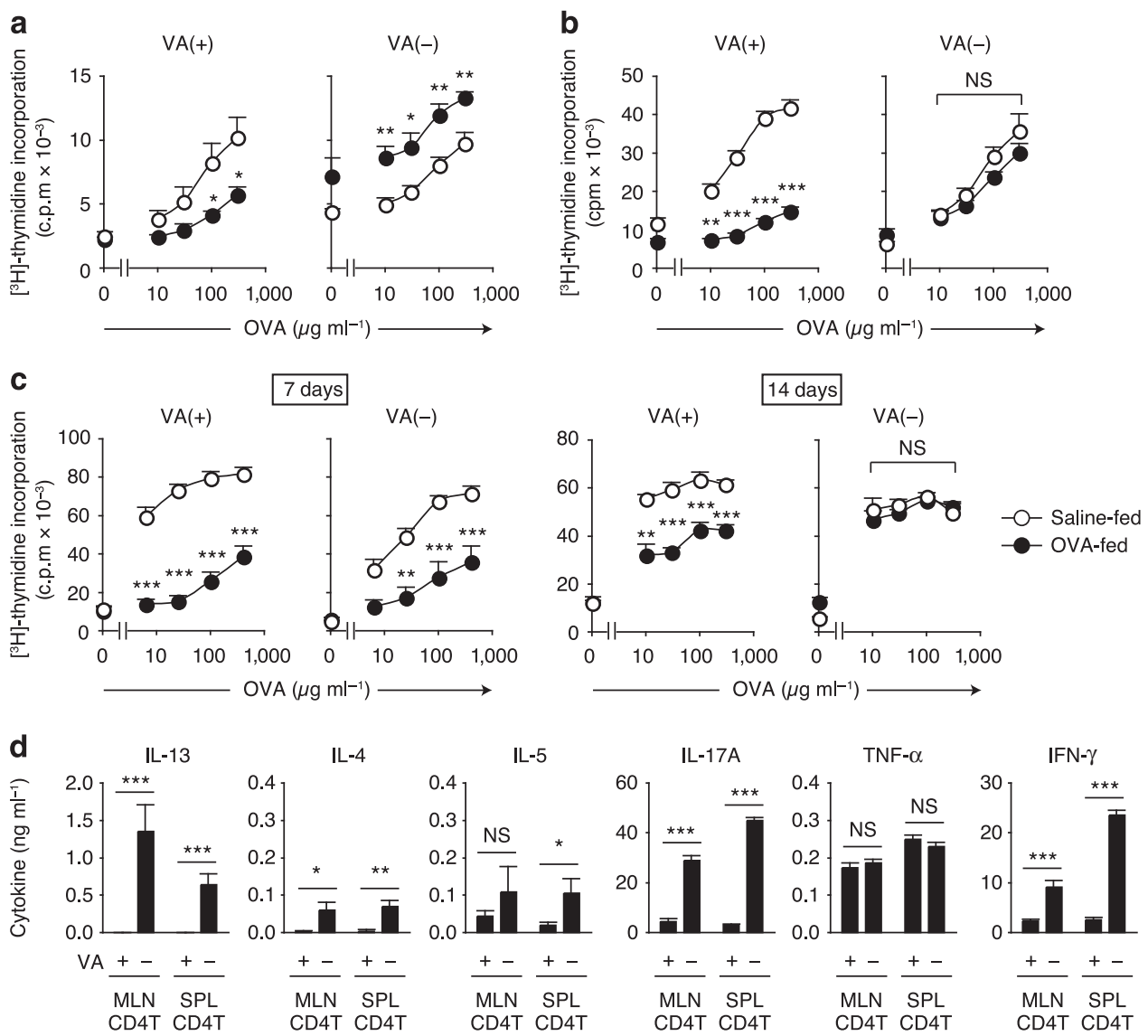

Figure 8 Vitamin $A(V A)$ deficiency compromises oral tolerance induction. $V A(+)$ and $V A(-)$ mice were fed with ovalbumin (OVA) or saline every other day for a total of five times. (a, b) OVA- or saline-fed mice were (a) immunized intraperitoneally with $0.1 \mathrm{mg}$ of OVA in alum ( $n=6-7 \mathrm{mice} / \mathrm{group}$ ) or (b) immunized intragastrically with $10 \mathrm{mg}$ of OVA plus cholera toxin ( $n=4 \mathrm{mice} / \mathrm{group}) 7$ days after the last feeding. OVA-specific proliferation of draining mesenteric lymph node (MLN) cells was assessed 7 days after immunization. (c) OVA- or saline-fed mice were immunized subcutaneously with $0.1 \mathrm{mg}$ of OVA in complete Freund's adjuvant 7 days after the last feeding. OVA-specific proliferation of draining peripheral lymph node cells was assessed 7 or 14 days after immunization ( $n=4-5$ mice/group). Data are presented as mean + s.e.m. for each group. ${ }^{*} P<0.05 ;{ }^{* *} P<0.01 ;{ }^{* *} P<0.001$; NS, not significant vs. treatment with the same concentration of OVA. (d) CD4 ${ }^{+}$cells were obtained from MLNs and spleens (SPLs) of OVA- or saline-fed mice without subsequent immunization $24 \mathrm{~h}$ after the last feeding. The cells were cultured with irradiated SPL cells and OVA for 3 days, and cytokine levels in the culture supernatants were assessed by enzyme-linked immunosorbent assay (ELISA). Data are presented as mean + s.d. of quadruplicate samples. Representative results from (a, d) four or (b, c) two independent experiments are shown.

is essential for the disruption of oral tolerance in $\mathrm{T}$ cells of $\mathrm{VA}(-)$ mice.

\section{DISCUSSION}

VA deficiency affects the nature of MLN-DCs even in unprimed mice. In particular, the $\mathrm{CD} 8 \alpha^{-} \mathrm{CD} 11 \mathrm{~b}^{+} \mathrm{CD} 103^{-}$ cDC (R2) subset of VA( - )MLN-DCs exhibited the ability to instruct naive $\mathrm{CD}^{+} \mathrm{T}$ cells to differentiate into IL-13producing inflammatory Th2 cells in an IL-6-dependent manner. IL-6 alone efficiently induced IL-13-producing inflammatory Th2 cells from naive $\mathrm{CD} 4{ }^{+} \mathrm{T}$ cells upon activation with antibodies to $\mathrm{CD} 3$ and $\mathrm{CD} 28$, indicating that IL-6-mediated signaling is essential and sufficient for IL-13-producing inflammatory Th2 induction in the absence of DCs. TGF- $\beta 1$ downregulated IL-13-producing inflammatory Th2 induction, and reciprocally upregulated Th17 induction, suggesting that TGF- $\beta$ levels in the microenvironment regulate the IL-13-producing inflammatory Th2/Th17 balance.

OX40/OX40L-mediated signaling also appeared to participate in IL-13-producing inflammatory Th2 induction by enhancing the generation of general inflammatory Th2 cells and suppressing that of Th17 cells. VA(-)MLN-DCs expressed much higher levels of Tnfsf4 than $\mathrm{VA}(+) \mathrm{MLN}$ DCs. However, among VA(-)MLN-DCs, the R3 subset expressed higher levels of Tnfsf4 than R2, despite the fact that R2 induced IL-13-producing inflammatory Th2 more efficiently than R3. An agonistic anti-OX40 antibody affected IL-13-producing inflammatory Th2/Th17 balance in the presence of MLN-DCs, suggesting that T cell/DC interactions mediated by other molecules could also be involved. In VA( - ) mice, TNF- $\alpha$ produced by epithelial cells in the proximal colon may flow into the draining MLNs and partly contribute to the induction of inflammatory Th2 cells by enhancing OX40L expression in MLN-DCs, although further analysis is necessary. 

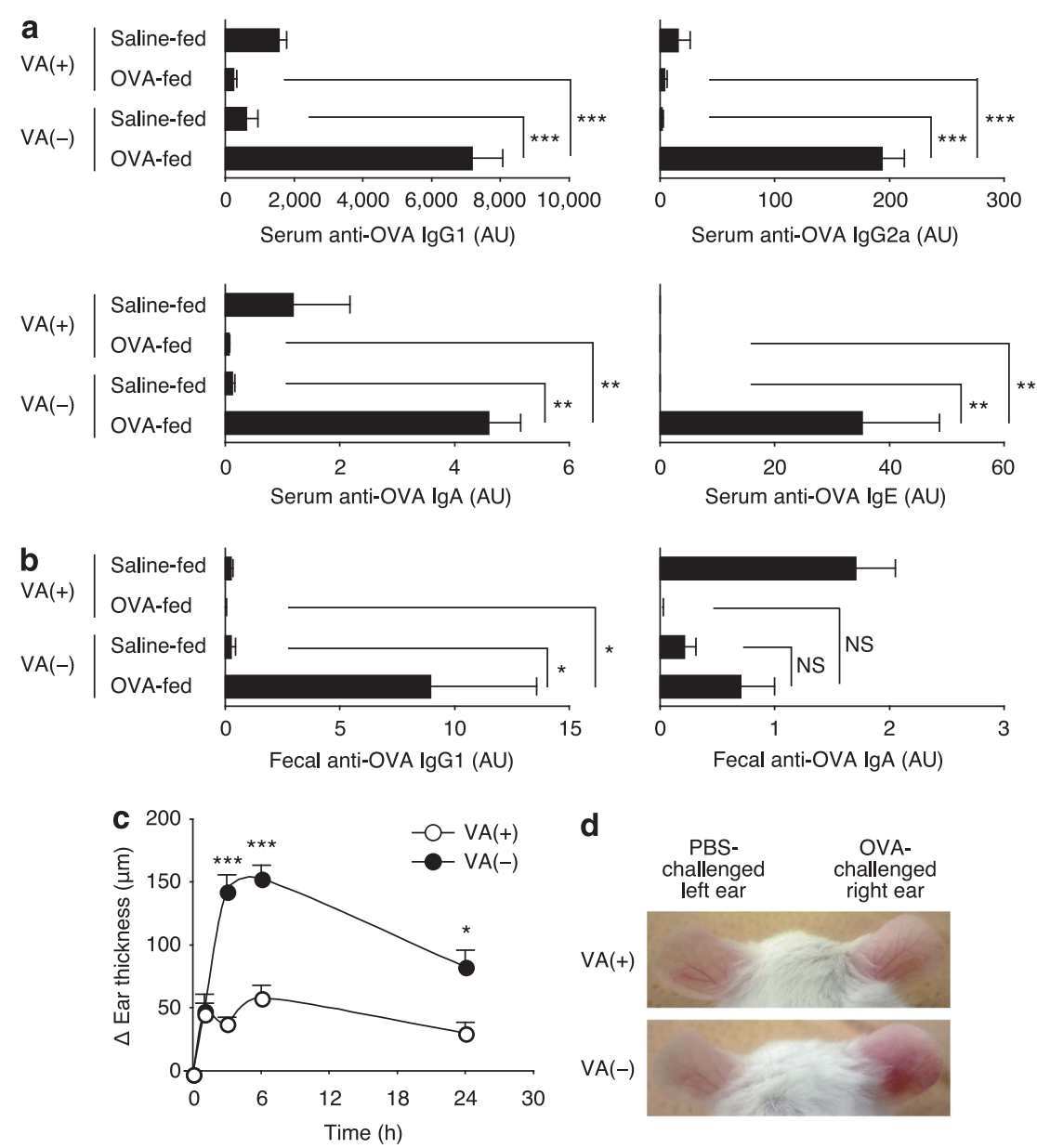

Figure 9 Repeated oral administration of ovalbumin (OVA) to vitamin A-deficient (VA $(-))$ mice primes for strong antibody responses. (a, b) OVA- or saline-fed $\mathrm{VA}(+)$ and $\mathrm{VA}(-)$ mice $(n=5$ mice/group) were immunized intraperitoneally (i.p.) with $0.1 \mathrm{mg}$ of OVA in alum 7 and 21 days after the last feeding. (a) The serum samples and (b) the fecal extracts were prepared 7 days after the last immunization, and were assessed by enzyme-linked immunosorbent assay (ELISA) for OVA-specific antibodies $(n=5 \mathrm{VA}(+)$ and $n=3 \mathrm{VA}(-)$ mice/group, two out of five OVA-fed or saline-fed $\mathrm{VA}(-)$ mice were dead after the second immunization). The antibody levels were defined by comparing with standard serum and expressed in arbitrary units (AU). Data are presented as mean + s.e.m. for each group. ${ }^{\star} P<0.05 ;{ }^{* \star} P<0.01$; ${ }^{* \star *} P<0.001$; NS, not significant. IgG1, immunoglobulin G1. (c) Ear thickness of OVA-fed and i.p. immunized mice was measured at the indicated time points after intradermal injection of $10 \mu \mathrm{g}$ of OVA into the right ear and phosphate-buffered saline (PBS) into the left ear. The differences between right and left ear thickness ( $\Delta$ ear thickness) are presented as mean + s.e.m., $n=4$ mice/group. ${ }^{\star} P<0.05 ;{ }^{* \star \star} P<0.001$. (d) Representative photographs of the ears taken $6 \mathrm{~h}$ after intradermal injection. Similar results were obtained from two independent experiments.

IL-12p40 also appeared to participate in the R2-mediated generation of IL-13-producing inflammatory Th2 but not Th17 cells. The homodimer IL-12p80 inhibits IL-12-mediated responses and contributes to Th2-type allergic diarrhea. ${ }^{38}$ Accordingly, IL-12p80 moderately enhanced Th2 induction. Th1-derived IFN- $\gamma$ is known to suppress both Th2 and Th17 differentiation. ${ }^{39}$ Interestingly, CD103 ${ }^{+}$MLN-DCs of VA( - ) mice produce IFN- $\gamma$ upon stimulation. ${ }^{40}$ IFN- $\gamma$ may contribute to the difference in the nature of $\mathrm{R} 2$ and $\mathrm{R} 3$. The nature of $\mathrm{R} 3$ may also be influenced by $\mathrm{CD}_{103}{ }^{+}$langerin ${ }^{+}$immunosuppressive DCs, which are found in VA(-)MLNs. ${ }^{22}$ R2- and R3-stimulated T cells produced low levels of IL-4, but these levels may still influence general Th2 skewing.

IL-13-producing inflammatory Th2 and Th17 may also influence each other. IL-13 attenuates Th17 cytokine production. ${ }^{41}$ However, IL-17A enhances downstream IL-13 signals. ${ }^{42}$
IL-13 appeared to be essential for the aberrant proliferation of $\mathrm{T}$ cells from $\mathrm{VA}(-)$ mice. The underlying mechanism remains to be clarified, but IL-13-producing inflammatory Th2 may have been the major influence on proliferating $\mathrm{T}$ cells in the MLN culture or could have induced IL-13-producing inflammatory Th2 proliferation in an autocrine manner. The complex interplay of cytokines is likely to influence IL-13-producing inflammatory Th2 induction.

IL-13-producing inflammatory Th2 cells induced by VA( - ) MLN-DCs expressed homing receptors for inflammatory sites or the skin. Indeed, these cells could migrate into inflamed skin. In $\mathrm{VA}(-)$ animals, the administration of food and bacterial antigens to the skin could thus pose a risk of IL-13-producing inflammatory Th2-dependent inflammation. IL-13-producing inflammatory Th2 cells that are primed in the MLNs could induce antigen-specific inflammatory responses in any tissues 

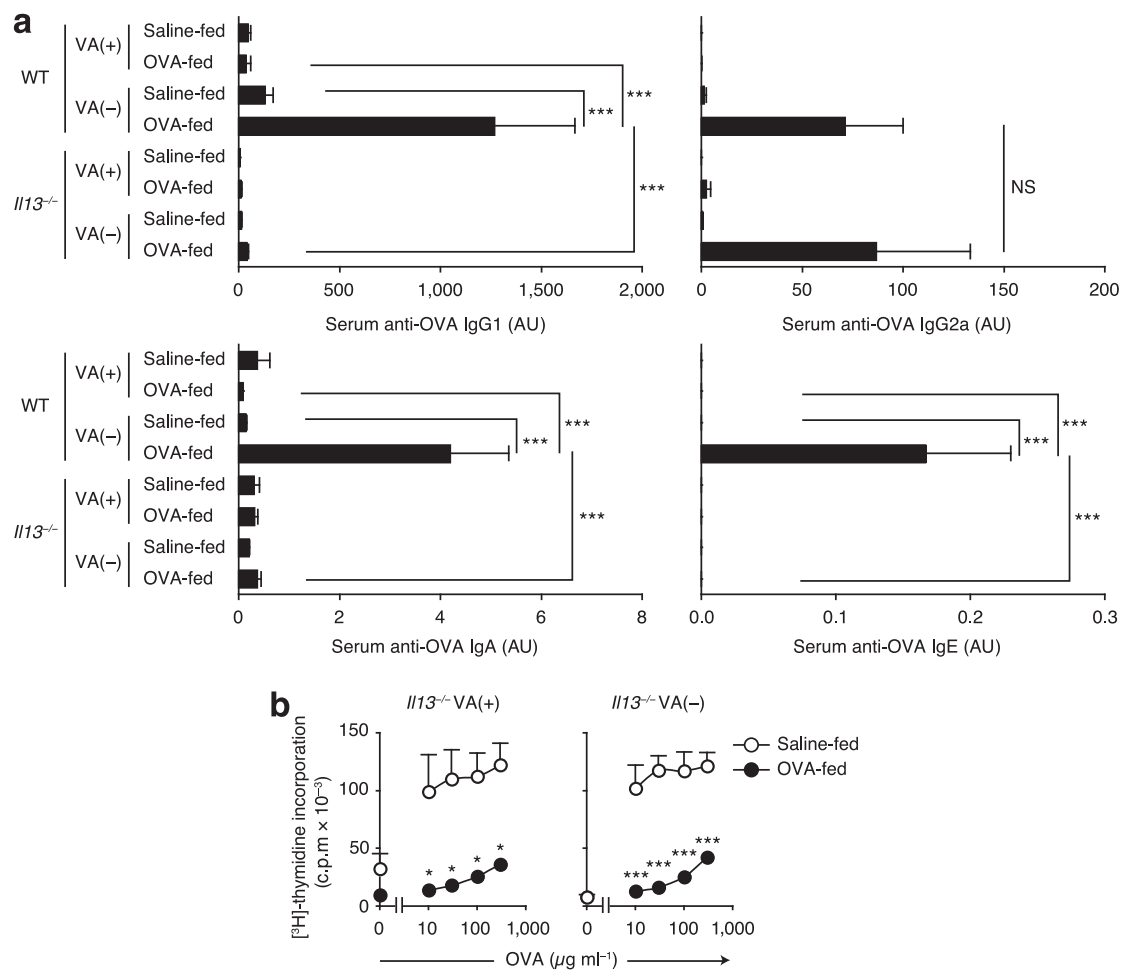

Figure 10 Interleukin-13 (IL-13) is essential for the enhanced anti-ovalbumin (OVA) antibody responses in vitamin $A$-deficient $(\mathrm{VA}(-))$ mice after OVA feeding. (a) OVA- or saline-fed wild-type (WT) VA(+), WT VA $(-)$, $I 113^{-}-\mathrm{VA}(+)$, and $I / 13^{-l-} \mathrm{VA}(-)$ mice $(n=4-7$ mice/group) were immunized intragastrically with $10 \mathrm{mg}$ of OVA plus cholera toxin 7,14 , and 21 days after the last feeding. The serum samples were prepared 7 days after the last immunization assessed by enzyme-linked immunosorbent assay for OVA-specific antibodies. The antibody levels were defined by comparing with standard serum and expressed in arbitrary units (AU). Data are presented as mean + s.e.m. for each group. ${ }^{* * *} P<0.001$. Representative results from three independent experiments are shown. IgG1, immunoglobulin G1. (b) OVA- or saline-fed $/ / 13^{-/-} \mathrm{VA}(+)$ and $/ / 13^{-\prime-}$ $\mathrm{VA}(-)$ mice were immunized intragastrically with $10 \mathrm{mg}$ of OVA plus cholera toxin 7 days after the last feeding. OVA-specific proliferation of draining mesenteric lymph node (MLN) cells was assessed 7 days after immunization. Data are presented as mean + s.e.m., 4 mice/group. ${ }^{\star} P<0.05$; ${ }_{* * *} P<0.001$.

with innate inflammation and blood-borne antigens that could be increased with repeated oral antigen administration or an infectious gut insult under VA( - ) conditions. ${ }^{43}$ Reductions in endogenous RA or VA concentrations have been observed in atopic dermatitis and other inflammatory diseases. ${ }^{44,45}$ Inflammatory Th2 cells often participate in these diseases. On the other hand, VA or RA treatment ameliorates various inflammatory diseases. ${ }^{46}$ IL-13 is known to play central roles in asthma. ${ }^{24-27}$ As CCR4 contributes to T-cell lung imprinting, ${ }^{47} \mathrm{IL}-13$-producing inflammatory Th2 cells may also be able to contribute to the antigen-specific asthmatic reaction. However, VA deficiency reduced disease severity in a mouse model of asthma induced by i.p. injections of OVA and alum, followed by exposures to aerosolized OVA. ${ }^{48}$ In the absence of OVA feeding, we also observed lower antibody responses in $\mathrm{VA}(-)$ mice compared with VA $(+)$ mice. Antigen prefeeding appears to be critical in inducing unusually high antibody responses in $\mathrm{VA}(-)$ mice. Nonetheless, relatively low dietary $\mathrm{VA}$ intake is known to be associated with asthma. ${ }^{49}$

Strong IgG1 responses and IgE responses were induced against OVA, a T cell-dependent antigen, in $\operatorname{VA}(-)$ mice. The IgE levels were sufficient to induce immediate-type allergic responses in the skin. However, previous reports suggested that
VA deficiency reduces antibody responses to T cell-dependent antigens and T cell-independent-type 2 antigens. ${ }^{12,13}$ On the other hand, VA deficiency in rats enhanced bacterial translocation into the MLNs and the serum levels of IgG, IgM, and IgE antibodies against bacterial antigens including the T cell-independent antigen lipopolysaccharide. ${ }^{13}$ Similarly, in unprimed mice, VA deficiency induced the elevation of serum IgG2a and IgG2b levels but not of IgG1, IgG3, or IgA levels. ${ }^{10,40}$ Commensal bacterial antigens such as lipopolysaccharide may contribute to this elevation. The strong IgG1 responses and IgE responses to OVA in the OVA-fed VA( - ) mice likely involve OVA-specific IL-13-producing inflammatory Th2 cells induced by $\mathrm{VA}(-) \mathrm{MLN}-\mathrm{DC}$. OVA feeding alone induced OVA-specific IL-13-producing CD4 ${ }^{+} \mathrm{T}$ cells in the MLNs of $\mathrm{VA}(-)$ mice. $\mathrm{T}$ cell-independent antigens derived from commensal bacteria may facilitate T-cell priming and the induction of antibody responses. Furthermore, additional adjuvant-induced signals may be necessary to trigger or enhance antibody responses.

Foxp $3^{+} \mathrm{CD} 103^{+} \mathrm{T}$ cells are present even in mice with low VA levels. ${ }^{50}$ Accordingly, VA( -$)$ PP-DCs induced Foxp ${ }^{+}$ $\mathrm{CD} 03^{+}{ }^{+}$-cell differentiation. The CCR9 ${ }^{+}$PP-pDCs in $\mathrm{VA}(-)$ mice may be tolerogenic, as their phenotype resembled 
that of tolerogenic CCR9 ${ }^{+}$pDCs. ${ }^{33}$ Nonetheless, in VA( - ) mice, oral antigen-specific inflammatory effector $\mathrm{T}$ cells including IL-13-producing inflammatory Th2 and Th17 appear to overcome the effect of regulatory $\mathrm{T}$ cells.

RA is required for immature DCs to express RALDH2, ${ }^{6,21,51}$ Bile retinoids contribute to the induction of RALDH2 expression in lamina propria-DCs and MLN-DCs. ${ }^{9}$ Therefore, liver dysfunction may affect RALDH2 expression in gut $\mathrm{CD} 103^{+}$DCs by reducing the production of bile retinoids and other components necessary for the intestinal absorption of lipids including RA precursors. Accordingly, young children with severe liver dysfunction have a high prevalence of food allergies, with specific IgE responses. ${ }^{52}$

The presence of RAR $\alpha$ appears to be critical for $\mathrm{CD} 4{ }^{+} \mathrm{T}$-cell activation and differentiation. ${ }^{18,53}$ In VA $(-)$ mice, weak RAR $\alpha$ signaling induced by residual levels of retinol or other molecules may be necessary for inducing inflammatory arms of immunity. Indeed, the retinol levels in our $\mathrm{VA}(-)$ mouse sera were $<1 / 10$ of the control but not completely absent. Therefore, the present results suggest that VA insufficiency in the gut increases the risk of IL-13-dependent inflammatory or allergic diseases by inducing oral antigen-specific IL-13producing inflammatory Th2 cells as well as the risk of Th17dependent diseases by changing the nature of MLN-DCs.

\section{METHODS}

Mice. BALB/c, C57BL/6, and DO11.10/Rag2 $2^{-1-}$ mice were obtained from CLEA Japan (Tokyo, Japan) and Taconic (Hudson, NY), respectively. BALB/c Ill3 ${ }^{-1-}$ mice were generated by backcrossing B6x129 Il13 ${ }^{-1-}$ mice (kindly provided by Dr Andrew McKenzie, MRC Laboratory of Molecular Biology, Cambridge, UK). ${ }^{36} \mathrm{VA}(-)$ and $\mathrm{VA}(+)$ mice were generated as previously described. ${ }^{6}$ All mice were maintained in specific pathogen-free conditions in the animal facility of Tokushima Bunri University (Kagawa, Japan). All animal experiments were performed according to protocols approved by the Animal Care and Use Committee of Tokushima Bunri University.

Cell preparation. DCs were isolated by MACS (Miltenyi Biotec, Bergisch Gladbach, Germany) as previously described. ${ }^{6}$ Sorting of DC subsets was performed on a FACSAria (BD, Franklin Lakes, NJ) after staining with fluorochrome-conjugated monoclonal antibodies (mAbs) against CD11c, B220, CD $\alpha \alpha, \mathrm{CD} 11 \mathrm{~b}$, and CD103 (Supplementary Table S1 online). Naive $\mathrm{CD} 4^{+} \mathrm{CD} 62 \mathrm{~L}^{\text {high }} \mathrm{T}$ cells were obtained from lymph nodes and SPLs of DO11.10/Rag2 ${ }^{-1-}$ mice by negative selection using EasySep Mouse CD4 ${ }^{+}$T Cell Enrichment Kits (Stemcell Technologies, Vancouver, BC, Canada). In some experiments, naive $\mathrm{CD} 4{ }^{+} \mathrm{CD} 62 \mathrm{~L}^{\text {high }} \mathrm{CD} 44^{-} \mathrm{T}$ cells were obtained from SPLs of $\mathrm{BALB} / \mathrm{c}$ or $\mathrm{C} 57 \mathrm{BL} / 6$ mice by negative selection using EasySep Mouse $\mathrm{CD}^{+}{ }^{+} \mathrm{T}$ Cell Enrichment Kits supplemented with biotinylated anti-CD44 mAb (IM7; BioLegend, San Diego, CA) and subsequently by positive selection with CD62L Microbeads (Miltenyi Biotec). To isolate proximal colon epithelial cells, the proximal colon was incubated with Hanks' balanced salt solution containing $1 \mathrm{~mm}$ dithiothreitol as previously described. ${ }^{6} \mathrm{BM}$ DCs were generated by culturing BM cells for 7 days in the presence of $20 \%$ culture supernatant of a mouse Flt3L-transfected CHO cell line, and then stimulated with $50 \mathrm{ng} \mathrm{ml}^{-1}$ TNF- $\alpha$ (Peprotech, Rocky Hill, $\mathrm{NJ}$ ) or $100 \mathrm{ng} \mathrm{ml}^{-1} \mathrm{IL}-33$ (BioLegend) in the presence or absence of $10 \mathrm{~nm}$ all-trans-RA for $48 \mathrm{~h}$.

Cell culture. DCs $\left(2-4 \times 10^{3}\right)$ were cocultured for 6 days with naive $\mathrm{CD}^{+} \mathrm{T}$ cells $\left(1-2 \times 10^{4}\right)$ from DO11.10/Rag2 ${ }^{-1-}$ mice in the presence of OVA peptide P323-339 $(1 \mu \mathrm{M})$ with or without all-transRA (10 nM; Sigma-Aldrich, St Louis, MO), LE135 (100 nM; Tocris Bioscience, Bristol, UK), LE540 (100 nм; Wako, Osaka, Japan), IL-6, IL-12p70, or IL-12p80 (10 $\mathrm{ng} \mathrm{ml}^{-1}$; BioLegend). In some experiments, neutralizing anti-IL-6 (MP5-20F3; BioLegend), anti-IL-12p40 (C17.8; BD), anti-IL-23p19 (G23-8; eBioscience, San Diego, CA), or antiOX40L (182601; R\&D Systems, Minneapolis, MN), agonistic antiOX40 (OX-86; eBioscience), Rat IgG1 isotype control (43414; R\&D Systems), or Rat IgG2a isotype control (54447; R\&D Systems) were used at $10 \mu \mathrm{g} \mathrm{ml}^{-1}$. For induction of regulatory $\mathrm{T}$ cells, cultures were supplemented with $5 \mathrm{ng} \mathrm{ml}^{-1}$ TGF- $\beta 1$ (Peprotech). For induction of Ccr 9 expression in T cells, DCs were pretreated with $1 \mu \mathrm{M}$ OVA peptide P323-339 for $2 \mathrm{~h}$, washed, and then cocultured with naive CD ${ }^{+}$ T cells. ${ }^{54}$ Naive CD $4{ }^{+}$T cells $\left(1 \times 10^{5}\right)$ from BALB/c or C57BL/6 mice were cultured for 3 days in the plates coated with anti-CD3 $\mathrm{mAb}$ $\left(3 \mu \mathrm{g} \mathrm{ml}^{-1}\right)$ and anti-CD28 $\mathrm{mAb}\left(3 \mu \mathrm{g} \mathrm{ml}^{-1}\right)$ with or without antiOX40 or Rat IgG1 isotype control $\left(10 \mu \mathrm{g} \mathrm{ml}^{-1}\right)$. The culture was diluted with twice its volume of fresh medium, transferred into new wells, and cultured for 3 days. Cytokines were added at the start of each culture. For the experiment in Figure 6b, TGF- $\beta 1$ (R\&D Systems) was used after reconstituting in $4 \mathrm{~mm}$ hydrochloric acid containing $1 \mathrm{mg} \mathrm{ml}^{-1}$ bovine serum according to the manufacturer's protocol. To assess T-cell cytokine production, the cells $\left(1 \times 10^{5}\right)$ were resuspended and cultured for 3 days in the plates coated with anti$\mathrm{CD} 3 \mathrm{mAb}\left(3 \mu \mathrm{g} \mathrm{ml}^{-1}\right)$ and anti-CD28 $\mathrm{mAb}\left(3 \mu \mathrm{g} \mathrm{ml}^{-1}\right)$. Cytokine levels in the culture supernatants were analyzed by enzyme-linked immunosorbent assay (ELISA).

Flow cytometry. Cells were stained with fluorochrome-conjugated mAbs (Supplementary Table S1) in the presence of anti-CD16/CD32 $\mathrm{mAb}(2.4 \mathrm{G} 2$; BD). Staining of E- and P-selectin ligands was performed as previously described. ${ }^{6}$ Intracellular staining of Foxp3 was performed using mouse/rat Foxp3 staining sets (eBioscience). For intracellular cytokine staining, $\mathrm{CD} 4{ }^{+} \mathrm{T}$ cells obtained from cultures were restimulated with immobilized anti-CD3 $\mathrm{mAb}\left(10 \mu \mathrm{g} \mathrm{ml}^{-1}\right)$ and soluble anti-CD28 mAb $\left(5 \mu \mathrm{g} \mathrm{ml}^{-1}\right)$ in the presence of monensin $(2 \mu \mathrm{M})$ for $6 \mathrm{~h}$. The cells were fixed and permeabilized with Fixation/ Permeabilization Buffers (eBioscience), and intracellular cytokine staining was performed according to the manufacturer's protocol. Analysis was performed on a FACSCalibur (BD) or FACSAria with CellQuest Pro software (BD).

Real-time PCR. Total RNA was isolated from cells using RNeasy Kit (Qiagen, Hilden, Germany), and complementary DNA was generated using QuantiTect Reverse Transcription Kit (Qiagen). Complementary DNA was used as a template for real-time PCR in triplicates with Power SYBR Green PCR Master Mix (Applied Biosystems, Foster City, CA) and gene-specific primers (Supplementary Table S2). PCR analyses were performed on a 7500 RealTime PCR system (Applied Biosystems). The expression of each gene was normalized with $R p l p 0$, and relative expression was quantified with the $2^{-\Delta C t}$ value multiplied by 1,000 .

Homing assay. $\mathrm{CD}^{+}$DO11.10/Rag2 ${ }^{-1-} \mathrm{T}$ cells activated with $\mathrm{VA}(+) \mathrm{MLN}-\mathrm{DCs}$ or VA(-)MLN-DCs were differentially labeled with 5-chloromethylfluorescein diacetate and SNARF ${ }^{\circledR}$-1 carboxylic acid acetate succinimidyl ester (Life Technologies, Carlsbad, CA) as previously described. ${ }^{55}$ An aliquot $\left(2-3 \times 10^{7}\right)$ of the cells was injected intravenously into each $\mathrm{BALB} / \mathrm{c}$ mouse with preexisting cutaneous inflammation in both ears induced by a standard delayed hypersensitivity protocol as previously described ${ }^{31}$ with modification. In brief, shaved abdomens of the mice were painted with $50 \mu \mathrm{l} 0.5 \%$ 2,4dinitro-1-fluorobenzene (Nacalai tesque, Kyoto, Japan) in acetone/ olive oil (4:1) on day 0 . On day 5, mice were challenged with $20 \mu 10.3 \%$ 2,4-dinitro-1-fluorobenzene on both ears, and used on the next day as recipients for competitive homing experiments. Recipients were killed $16 \mathrm{~h}$ after the adoptive transfer, and the transferred cells were recovered from MLNs and both ears after digestion with collagenase 
type VIII (Sigma-Aldrich). To assess the migration efficiency of the transferred cells, the ratios of SNARF- ${ }^{+}$cells/CMFDA ${ }^{+}$cells in recipient tissues were analyzed by flow cytometry.

Immunohistochemical analysis. MLNs, tissue blocks of the small intestine with PP, proximal colon, and ear from $\mathrm{VA}(+)$ and $\mathrm{VA}(-)$ mice were immersion-fixed in $4 \%$ paraformaldehyde in $0.1 \mathrm{M}$ phosphate buffer ( $\mathrm{pH} 7.2$ ). The fixed tissues were immersed in $20 \%$ sucrose in $0.1 \mathrm{~m}$ phosphate buffer overnight for cryoprotection, embedded in O.C.T. compound (Sakura Finetek Japan, Tokyo, Japan), and then frozen on dry ice. Frozen sections ( $8 \mu \mathrm{m}$ thick) of these tissues were cut out and thaw-mounted onto silane-coated glass slides. These sections were blocked with 5\% normal donkey serum (Jackson ImmunoResearch, West Grove, PA) for $1 \mathrm{~h}$ at room temperature. The sections were incubated with rabbit anti-TNF- $\alpha$ (Abcam, Cambridge, MA) at $4{ }^{\circ} \mathrm{C}$ for at least $48 \mathrm{~h}$ followed by the incubation with Cy3-conjugated donkey anti-rabbit IgG (Jackson ImmunoResearch) for $1 \mathrm{~h}$ at room temperature. TO-PRO-3 (Molecular Probes, Eugene, OR) was used for nuclear staining. Immunostained sections were coverslipped with glycerol and observed using a confocal laser scanning microscopy (FV-1000; Olympus, Tokyo, Japan).

Induction of oral tolerance and immunization. Mice were fed $10 \mathrm{mg}$ of OVA (grade V; Sigma-Aldrich) or saline alone by gavage 5 times every other day (on days $0,2,4,6$, and 8 ). The mice were immunized with $0.1 \mathrm{mg}$ of OVA in adjuvant $(2 \mathrm{mg}$ of Imject Alum (Thermo Fisher Scientific, Waltham, MA) for i.p., or complete Freund's adjuvant (Sigma-Aldrich) for subcutaneous administration) 7 days after the last feeding (day 15). In some experiments, the mice were immunized intragastrically with $10 \mathrm{mg}$ of OVA and $10 \mu \mathrm{g}$ of cholera toxin (List Biological Laboratories, Campbell, CA). OVA-specific proliferation of draining lymph node cells was assessed 7 or 14 days after immunization (day 22 or 29). To assess antibody responses, OVA- or salinefed mice were immunized i.p. with $0.1 \mathrm{mg}$ of OVA in alum 7 and 21 days after the last feeding (on days 15 and 29), whereas the other mice were immunized intragastrically with $10 \mathrm{mg}$ of OVA plus cholera toxin 7,14 , and 21 days after the last feeding (on days 15, 22, and 29). The serum and the rectal feces of each mouse were collected 7 days after the last immunization (day 36). Feces were adjusted to a $100 \mathrm{mg} \mathrm{ml}^{-1}$ concentration in phosphate-buffered saline containing protease inhibitors (Complete, Mini; Roche Applied Science, Indianapolis, IN) and $0.1 \%$ sodium azide. The feces were homogenized, incubated for $1 \mathrm{~h}$ on ice, and centrifuged for $15 \mathrm{~min}$ at 20,000 $\mathrm{g}$ to remove solid material. To assess CD4 ${ }^{+}$T-cell cytokine production, MLNs and SPLs were obtained from the OVA- or saline-fed mice without subsequent immunization $24 \mathrm{~h}$ after the last feeding. $\mathrm{CD} 4{ }^{+}$cells were isolated by positive selection with CD4 Microbeads (Miltenyi Biotec). Aliquots $\left(4 \times 10^{5}\right)$ were cultured with irradiated SPL cells $\left(1 \times 10^{6}\right)$ and OVA $\left(1 \mathrm{mg} \mathrm{ml}^{-1}\right)$ for 3 days. Cytokine levels in the culture supernatants were analyzed by ELISA.

Antigen-induced ear swelling assay. $\mathrm{VA}(+)$ and $\mathrm{VA}(-)$ mice fed OVA 5 times were immunized with two i.p. injections of OVA/alum as described above. At 7 days after the last immunization, the left ears of mice were intradermally administered with $10 \mu \mathrm{g}$ of OVA in $10 \mu \mathrm{l}$ of phosphate-buffered saline, and their right ears were administered an equal amount of phosphate-buffered saline by using a microsyringe (1701LT; Hamilton, Reno, NV). Ear thickness was measured with a dial thickness gage (No. 7331; Mitsutoyo, Kanagawa, Japan).

Proliferation assay. Single-cell suspensions were prepared from draining MLNs or PLNs (inguinal and popliteal lymph nodes) of individual mice and cultured at $5 \times 10^{5}$ cells with graded concentrations of OVA for 4 days. The cells were pulsed with $1 \mu \mathrm{Ci}$ of $\left[{ }^{3} \mathrm{H}\right]$-thymidine for the last $16 \mathrm{~h}$ of culture and their radioactivity was counted on a 1450 Microbeta TriLux (PerkinElmer, Waltham, MA).

ELISA. Cytokine levels in the culture supernatants were analyzed with ELISA kits for IFN- $\gamma$, IL-4, IL-5, IL-6, IL-10, IL-12p40, IL-12p70,
TNF- $\alpha$ (BD), IL-9, IL-17A, IL-23p19 (BioLegend), IL-13, and IL-21 (R\&D Systems). To detect OVA-specific antibodies, plates were coated with $20 \mathrm{mg} \mathrm{ml}^{-1}$ OVA in $0.05 \mathrm{M}$ carbonate-bicarbonate buffer ( $\mathrm{pH}$ 9.6), and blocked with 5\% normal goat serum (Sigma-Aldrich) in Tris-buffered saline. Serially diluted serum samples or fecal extracts and standard serum (pooled hyperimmune sera collected after i.p. immunization with $0.1 \mathrm{mg}$ of OVA in alum 3 times at 2-week intervals) were added and incubated for $2 \mathrm{~h}$. After washing, horseradish peroxidase-conjugated goat anti-mouse IgG1, IgG2a, or IgA (Bethyl Laboratories, Montgomery, TX) were added and incubated for $1 \mathrm{~h}$. To detect anti-OVA IgE, biotinylated anti-mouse IgE (BioLegend) was added for $1 \mathrm{~h}$, followed by addition of horseradish peroxidaseconjugated avidin (BioLegend). The reactions were developed with 3,3',5,5'-tetramethylbenzidine substrate (Sigma-Aldrich) and stopped with $1 \mathrm{M} \mathrm{H}_{2} \mathrm{SO}_{4}$. The absorbance at $450 \mathrm{~nm}$ was measured using a microplate reader (Bio-Rad Laboratories, Hercules, CA). OVA-specific antibody levels were defined by comparing with standard serum and expressed in arbitrary units (AU). Total antibodies were analyzed with ELISA kits for mouse IgG1, IgG2a, IgA (Bethyl Laboratories), and IgE (BioLegend).

Statistical analysis. Statistical comparisons were carried out using the one-way analysis of variance with Tukey-Kramer multiple comparisons test and the two-tailed unpaired Student's $t$-test. Values $<0.05$ were considered statistically significant.

SUPPLEMENTARY MATERIAL is linked to the online version of the paper at http://www.nature.com/mi

\section{ACKNOWLEDGMENTS}

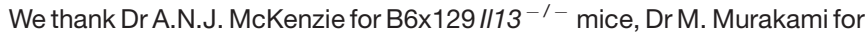
Flt3L-transfected $\mathrm{CHO}$ cell line, Dr K. Ishizaka for critical reading of the manuscript, Dr M. Kubo for intracellular IL-13-staining method, and Ms N. Uemura, H. Tanihigashi-Hayase, and M. Oda for technical assistance. This work was supported by a Grant-in-Aid for Young Scientists (B) (to A.Y.-N.), grants from Uehara Memorial Foundation (to M.I.), The Danone Institute of Japan Research Grant (to M.I.), and JST, CREST (to M.I.), and a Grant-in-Aid for Scientific Research (B) from the Ministry of Education, Science, Sports and Culture of Japan (to M.I.).

\section{DISCLOSURE}

The authors declared no conflict of interest.

c 2014 Society for Mucosal Immunology

\section{REFERENCES}

1. Imdad, A., Yakoob, M.Y., Sudfeld, C., Haider, B.A., Black, R.E. \& Bhutta, Z.A. Impact of vitamin A supplementation on infant and childhood mortality. BMC Public Health 11 (Suppl 3), S20 (2011)2011).

2. Hofmann, A.F. The continuing importance of bile acids in liver and intestinal disease. Arch. Intern. Med. 159, 2647-2658 (1999).

3. Laffont, S., Siddiqui, K.R. \& Powrie, F. Intestinal inflammation abrogates the tolerogenic properties of MLN CD103 ${ }^{+}$dendritic cells. Eur. J. Immunol. 40, 1877-1883 (2010).

4. Clugston, R.D. \& Blaner, W.S. The adverse effects of alcohol on vitamin A metabolism. Nutrients 4, 356-371 (2012).

5. Iwata, M., Hirakiyama, A., Eshima, Y., Kagechika, H., Kato, C. \& Song, S.Y. Retinoic acid imprints gut-homing specificity on $\mathrm{T}$ cells. Immunity 21, 527-538 (2004).

6. Yokota, A. et al. GM-CSF and IL-4 synergistically trigger dendritic cells to acquire retinoic acid-producing capacity. Int. Immunol. 21, 361-377 (2009).

7. Coombes, J.L. et al. A functionally specialized population of mucosal $\mathrm{CD}_{103}{ }^{+}$DCs induces Foxp3 ${ }^{+}$regulatory T cells via a TGF- $\beta$ and retinoic acid-dependent mechanism. J. Exp. Med. 204, 1757-1764 (2007).

8. Sun, C.M. et al. Small intestine lamina propria dendritic cells promote de novo generation of Foxp3 T reg cells via retinoic acid. J. Exp. Med. 204, 1775-1785 (2007). 
9. Jaensson-Gyllenback, E. et al. Bile retinoids imprint intestinal $C D 103^{+}$ dendritic cells with the ability to generate gut-tropic T cells. Mucosal Immunol. 4, 438-447 (2011).

10. Mora, J.R. et al. Generation of gut-homing IgA-secreting B cells by intestinal dendritic cells. Science 314, 1157-1160 (2006).

11. Iwata, M. \& Yokota, A. Retinoic acid production by intestinal dendritic cells. Vitam. Horm. 86, 127-152 (2011).

12. Ross, A.C., Chen, Q. \& Ma, Y. Augmentation of antibody responses by retinoic acid and costimulatory molecules. Semin. Immunol. 21, 42-50 (2009).

13. Wiedermann, U., Hanson, L.A., Bremell, T., Kahu, H. \& Dahlgren, U.I. Increased translocation of Escherichia coli and development of arthritis in vitamin A-deficient rats. Infect. Immun. 63, 3062-3068 (1995).

14. Mucida, D. et al. Reciprocal $T_{H} 17$ and regulatory $T$ cell differentiation mediated by retinoic acid. Science 317, 256-260 (2007).

15. Curotto de Lafaille, M.A., Kutchukhidze, N., Shen, S., Ding, Y., Yee, H. \& Lafaille, J.J. Adaptive $\mathrm{Foxp}^{+}$regulatory $\mathrm{T}$ cell-dependent and -independent control of allergic inflammation. Immunity 29, 114-126 (2008).

16. Hadis, U. et al. Intestinal tolerance requires gut homing and expansion of FoxP $3^{+}$regulatory $\mathrm{T}$ cells in the lamina propria. Immunity $34,237-246$ (2011).

17. Cassani, B. et al. Gut-tropic T cells that express integrin $\alpha 4 \beta 7$ and CCR9 are required for induction of oral immune tolerance in mice. Gastroenterology 141, 2109-2118 (2011).

18. Hall, J.A. et al. Essential role for retinoic acid in the promotion of $\mathrm{CD} 4^{+}$Tcell effector responses via retinoic acid receptor alpha. Immunity 34 , 435-447 (2011).

19. Uematsu, S. et al. Regulation of humoral and cellular gut immunity by lamina propria dendritic cells expressing Toll-like receptor 5. Nat. Immunol. 9, 769-776 (2008)

20. DePaolo, R.W. et al. Co-adjuvant effects of retinoic acid and IL-15 induce inflammatory immunity to dietary antigens. Nature 471, 220-224 (2011).

21. Villablanca, E.J. et al. MyD88 and retinoic acid signaling pathways interact to modulate gastrointestinal activities of dendritic cells. Gastroenterology 141, 176-185 (2011).

22. Chang, S.Y. et al. Lack of retinoic acid leads to increased langerinexpressing dendritic cells in gut-associated lymphoid tissues. Gastroenterology 138, 1468-1478. 1478 e1461-1466 (2010).

23. Huber, S., Gagliani, N. \& Flavell, R.A. Life, death, and miracles: Th17 cells in the intestine. Eur. J. Immunol. 42, 2238-2245 (2012).

24. Zhu, Z. et al. Pulmonary expression of interleukin-13 causes inflammation, mucus hypersecretion, subepithelial fibrosis, physiologic abnormalities, and eotaxin production. J. Clin. Invest. 103, 779-788 (1999).

25. Wynn, T.A. IL-13 effector functions. Annu. Rev. Immunol. 21, 425-456 (2003).

26. Wills-Karp, M. Interleukin-13 in asthma pathogenesis. Immunol. Rev. 202, 175-190 (2004).

27. Munitz, A., Brandt, E.B., Mingler, M., Finkelman, F.D. \& Rothenberg, M.E. Distinct roles for IL-13 and IL-4 via IL-13 receptor $\alpha 1$ and the type II IL-4 receptor in asthma pathogenesis. Proc. Natl. Acad. Sci. USA 105 7240-7245 (2008).

28. Fuss, I.J. \& Strober, W. The role of IL-13 and NKT cells in experimental and human ulcerative colitis. Mucosal Immunol. 1 (Suppl 1), S31-S33 (2008).

29. Hoving, J.C. et al. B cells that produce immunoglobulin $E$ mediate colitis in BALB/c mice. Gastroenterology 142, 96-108 (2012).

30. Akdis, M., Akdis, C.A., Weigl, L., Disch, R. \& Blaser, K. Skin-homing, CLA ${ }^{+}$ memory $T$ cells are activated in atopic dermatitis and regulate IgE by an IL-13-dominated cytokine pattern: IgG4 counter-regulation by $\mathrm{CLA}^{-}$memory T cells. J. Immunol. 159, 4611-4619 (1997).

31. Mora, J.R., Cheng, G., Picarella, D., Briskin, M., Buchanan, N. \& von Andrian, U.H. Reciprocal and dynamic control of CD8 T cell homing by dendritic cells from skin- and gut-associated lymphoid tissues. J. Exp. Med. 201, 303-316 (2005).

32. Ito, T. et al. TSLP-activated dendritic cells induce an inflammatory Thelper type 2 cell response through OX40 ligand. J. Exp. Med. 202, 1213-1223 (2005).

33. Hadeiba, H., Sato, T., Habtezion, A., Oderup, C., Pan, J. \& Butcher, E.C. CCR9 expression defines tolerogenic plasmacytoid dendritic cells able to suppress acute graft-versus-host disease. Nat. Immunol. 9, 1253-1260 (2008).

34. Besnard, A.G., Togbe, D., Guillou, N., Erard, F., Quesniaux, V. \& Ryffel, B. IL-33-activated dendritic cells are critical for allergic airway inflammation. Eur. J. Immunol. 41, 1675-1686 (2011).

35. Nakae, S. et al. Mast cells enhance Tcell activation: importance of mast cell costimulatory molecules and secreted TNF. J. Immunol. 176, 2238-2248 (2006).

36. McKenzie, G.J. et al. Impaired development of Th2 cells in IL-13-deficient mice. Immunity 9, 423-432 (1998).

37. Mitsdoerffer, M. Proinflammatory T helper type 17 cells are effective B-cell helpers. Proc. Natl. Acad. Sci. USA 107, 14292-14297 (2010).

38. Hino, A., Kweon, M.N., Fujihashi, K., McGhee, J.R. \& Kiyono, H. Pathological role of large intestinal IL-12p40 for the induction of Th2type allergic diarrhea. Am. J. Pathol. 164, 1327-1335 (2004).

39. Hu, X. \& Ivashkiv, L.B. Cross-regulation of signaling pathways by interferongamma: implications for immune responses and autoimmune diseases. Immunity 31, 539-550 (2009).

40. Chang, J.H., Cha, H.R., Chang, S.Y., Ko, H.J., Seo, S.U. \& Kweon, M.N. IFN- $\gamma$ secreted by $\mathrm{CD}_{103}{ }^{+}$dendritic cells leads to IgG generation in the mesenteric lymph node in the absence of vitamin A. J. Immunol. 186, 6999-7005 (2011).

41. Newcomb, D.C. et al. A functional IL-13 receptor is expressed on polarized murine CD4 ${ }^{+}$Th17 cells and IL-13 signaling attenuates Th17 cytokine production. J. Immunol. 182, 5317-5321 (2009).

42. Lajoie, S. et al. Complement-mediated regulation of the IL-17A axis is a central genetic determinant of the severity of experimental allergic asthma. Nat. Immunol. 11, 928-935 (2010).

43. Ahmed, F., Jones, D.B. \& Jackson, A.A. The interaction of vitamin A deficiency and rotavirus infection in the mouse. Br. J. Nutr. 63, 363-373 (1990).

44. Gudas, L.J. Emerging roles for retinoids in regeneration and differentiation in normal and disease states. Biochim. Biophys. Acta 1821, 213-221 (2012).

45. Mihaly, J., Gamlieli, A., Worm, M. \& Ruhl, R. Decreased retinoid concentration and retinoid signalling pathways in human atopic dermatitis. Exp. Dermatol. 20, 326-330 (2011).

46. Collins, C.B. et al. Retinoic acid attenuates ileitis by restoring the balance between T-helper 17 and T regulatory cells. Gastroenterology 141, 1821-1831 (2011).

47. Mikhak, Z., Strassner, J.P. \& Luster, A.D. Lung dendritic cells imprint T cell lung homing and promote lung immunity through the chemokine receptor CCR4. J. Exp. Med. 210, 1855-1869 (2013).

48. Schuster, G.U., Kenyon, N.J. \& Stephensen, C.B. Vitamin A deficiency decreases and high dietary vitamin $A$ increases disease severity in the mouse model of asthma. J. Immunol. 180, 1834-1842 (2008).

49. Allen, S., Britton, J.R. \& Leonardi-Bee, J.A. Association between antioxidant vitamins and asthma outcome measures: systematic review and meta-analysis. Thorax 64, 610-619 (2009).

50. Kang, S.G., Wang, C., Matsumoto, S. \& Kim, C.H. High and low vitamin A therapies induce distinct FoxP3 ${ }^{+}$T-cell subsets and effectively control intestinal inflammation. Gastroenterology 137, 1391-1402 e1391-1396 (2009).

51. Iliev, I.D. et al. Human intestinal epithelial cells promote the differentiation of tolerogenic dendritic cells. Gut 58, 1481-1489 (2009).

52. Brown, C. et al. High prevalence of food sensitisation in young children with liver disease: a clue to food allergy pathogenesis? Pediatr. Allergy Immunol. 23, 771-778 (2012).

53. Pino-Lagos, K. et al. A retinoic acid-dependent checkpoint in the development of $\mathrm{CD}^{+}{ }^{+} \mathrm{T}$ cell-mediated immunity. J. Exp. Med. 208, 1767-1775 (2011).

54. Ohoka, Y., Yokota, A., Takeuchi, H., Maeda, N. \& Iwata, M. Retinoic acidinduced CCR9 expression requires transient TCR stimulation and cooperativity between NFATC2 and the retinoic acid receptor/retinoid X receptor complex. J. Immunol. 186, 733-744 (2011).

55. Takeuchi, $\mathrm{H}$. et al. Efficient induction of CCR9 on $\mathrm{T}$ cells requires coactivation of retinoic acid receptors and retinoid $X$ receptors (RXRs): exaggerated $T$ Cell homing to the intestine by RXR activation with organotins. J. Immunol. 185, 5289-5299 (2010). 